\title{
Private Information, Wage Bargaining and Employment Fluctuations
}

\author{
JOHN KENNAN \\ University of Wisconsin and NBER
}

First version received June 2006; final version accepted March 2009 (Eds.)

\begin{abstract}
Shimer (2005) pointed out that although we have a satisfactory theory of why some workers are unemployed at any given time, we don't know why the number of unemployed workers varies so much over time. The basic Mortensen-Pissarides model does not generate nearly enough volatility in unemployment for plausible parameter values. This paper extends the Mortensen-Pissarides model to allow for informational rents. Productivity is subject to publicly observed aggregate shocks, and to idiosyncratic shocks that are seen only by the employer. It is shown that there is a unique equilibrium, provided that the idiosyncratic shocks are not too large. The main result is that small fluctuations in productivity that are privately observed by employers can give rise to a kind of wage stickiness in equilibrium, and the informational rents associated with this stickiness are sufficient to generate relatively large unemployment fluctuations.
\end{abstract}

\section{INTRODUCTION}

The standard view of unemployment is that it takes time for workers to find the right job, and for employers to find the right worker. Fluctuations in the productivity of jobs naturally give rise to fluctuations in the number of workers looking for jobs, and in the number of employers looking for workers. High productivity is associated with a tight labour market in which more workers have jobs and fewer workers are looking for jobs, while employers are keen to hire more workers, so vacancies are plentiful; conversely, when productivity is low, unemployment is high and there are few vacancies.

This simple description of the source of unemployment fluctuations suggests that it should be possible to measure the variability of productivity and use this to explain the variability of unemployment, to a rough approximation. The Mortensen and Pissarides (1994) model is the natural framework for such a calculation, since it gives a precise account of the relationship between productivity and search on each side of the labour market. Shimer (2005) showed that the basic Mortensen-Pissarides model in fact translates fluctuations in labour productivity into unemployment fluctuations that are very much smaller than those seen in the US data. Thus, although we have a satisfactory theory of why some workers are unemployed at any given time, we do not know why the number of unemployed workers varies so much over time. To a substantial extent, the number of unemployed workers varies because of movements into and out of the labour force, which are not included in the Mortensen-Pissarides model. But even for people who are firmly attached to the labour force, the variations are large. For example, in the US over the period 1967-2008, the median annual unemployment rate of white men 
aged $35-39$ was $3.65 \%$; in 10 of these 40 years, the rate was $4.4 \%$ or higher, while there were 11 years with a rate of $2.6 \%$ or lower. The basic reason for unemployment in this group is that no two workers are the same, and no two jobs are the same. Given that job separation rates are relatively stable, the unemployment rate is a measure of how long it takes to match workers and jobs. The question then is why the matching process should be so much slower in some years than in others.

Hall (2005) argued that this volatility problem can be fixed if the Nash bargaining component of the Mortensen-Pissarides model is replaced by a "sticky" wage-setting process. Brügemann and Moscarini (2009) showed that the volatility of unemployment remains implausibly low for a broad class of surplus-sharing rules: the Nash bargaining rule is not an isolated case. On the other hand, when there is some stickiness in wages, the employers' incentive to create vacancies is magnified when the economy improves, and this increases unemployment volatility. Brügemann and Moscarini (2009) show that unless there is enough stickiness to generate countercyclical fluctuations in the rents accruing to workers, the job creation incentive cannot vary enough to match the unemployment volatility data.

As Rotemberg (2006) points out, the basic Mortensen-Pissarides model also predicts procyclical wages, which are not seen in the data, and this problem persists in the more general model developed by Yashiv (2006). Wage stickiness helps to resolve this discrepancy as well, but of course this is useful only if we understand why wages are sticky. Hall (2005) assumed that the wage level in a previous contract establishes a "social norm" that largely determines the wage in the next contract. In the absence of a theory of social norms, this explanation is incomplete. Similarly, Gertler and Trigari (2009) showed that staggered wage contracts magnify the incentive to create vacancies, but did not try to explain why workers and employers who are interested only in the present value of income would negotiate contracts that fix the wage in matches that have not yet been made.

This paper shows that an extension of the Mortensen-Pissarides model in which some productivity fluctuations are privately observed by employers can explain the volatility of unemployment in a more parsimonious way. The introduction of private information precludes the Nash bargaining rule; instead, the surplus is divided using Myerson's neutral bargaining solution (NBS), which generalizes the Nash bargaining solution to allow for private information. There are two main results. First, the extended model has a unique equilibrium. Second, this equilibrium exhibits a kind of wage stickiness, and the informational rents associated with this stickiness are sufficient to translate small fluctuations in productivity into large unemployment fluctuations. Menzio (2005) develops this idea in great detail, and derives an equilibrium in which transient productivity fluctuations that are privately observed by employers are not transmitted to wages. In Menzio's model, employers post wages, and wages are sticky because the gains from using high wages to attract more workers when productivity is high are more than offset by the losses from having to pay higher wages to current employees. In this paper, on the other hand, wages are determined through bargaining after a job match is found, and wage stickiness is a feature of the bargaining equilibrium.

Brügemann and Moscarini (2009) consider generalizations of the Mortensen-Pissarides model in which both employers and workers have private information about the job match surplus, and they analyse a representative selection of bargaining models that yield procyclical worker rents, and therefore insufficient unemployment volatility. But their analysis is confined to situations in which the extent of private information does not change over the cycle, so there is no scope for procyclical informational rents, which is the main focus of the analysis in this paper. 


\section{A MODEL OF STICKY WAGES WITH PRIVATE INFORMATION AND AGGREGATE SHOCKS}

A job match generates a surplus to be divided between the worker and the employer. The value of the worker's output is the sum of two components, $p+y$, where $p$ is common to all matches, and $y$ is a random idiosyncratic component whose realization ( $L$ for low or $H$ for high) is observed privately by the employer when the match is made. The aggregate component $p$ is a publicly observed Markov pure jump process with two states ( $s=1$ in the bad state and $s=2$ in the good state), and exit hazards $\lambda_{1}$ and $\lambda_{2}$. The high value of $y$ has probability $\tau_{s}$, depending on the aggregate state. The flow surplus is $p+y-y_{0}>0$, where $y_{0}>0$ is the flow value of unemployment (including unemployment benefits and the value of leisure). The expectation of the surplus is assumed to be higher in the good state.

When the joint continuation value from a match falls below the joint opportunity cost, the match is destroyed. The job destruction hazard rate is a constant, $\delta$, and there is a constant returns matching function that generates a flow of new matches $M\left(N_{\mathrm{U}}, N_{\mathrm{V}}\right)$ from unemployment and vacancy stocks $N_{\mathrm{U}}$ and $N_{\mathrm{V}}$. There is an infinitely elastic supply of potential vacancies, and the actual number of vacancies posted is such that the expected profit from a vacancy is zero. Workers and employers maximize the present value of net income, using the interest rate $r$.

In the Mortensen-Pissarides model, the match surplus is divided according to the Nash Bargaining Solution. In the model considered here, the surplus is not common knowledge, so this solution is not applicable. What is needed is a generalization of Nash's argument to cover bargaining problems involving private information. A natural choice is the NBS developed by Myerson (1984). The NBS coincides with the Nash solution under complete information, and in the more general case it divides the surplus equitably while respecting the incentive compatibility constraints arising from the existence of private information. Myerson (1984) shows that an NBS always exists, and provides a characterization that is relatively tractable in simple cases.

In Appendix $\mathrm{A}$ it is shown that for the bargaining problem considered in this paper, the NBS is unique, and it can be implemented by Myerson's Random Dictator mechanism. This means that the surplus is divided in the following way. Either the employer or the worker is randomly selected to make an offer, and if this offer is rejected the match dissolves. Clearly, the employer's offer will just match the worker's reservation level, which is the value of searching for another match. The worker effectively has two choices: an offer that exhausts the low surplus, with a sure acceptance, or an offer that exhausts the high surplus, with acceptance only if the high surplus has actually been realized. It will be assumed that the parameters are such that the worker always finds it optimal to demand the low surplus, conceding the difference between the high and the low surplus to the employer as an informational rent.

It is also useful to consider a simple modification of the NBS in which the parties have unequal bargaining weights. ${ }^{1}$ For example, Hagedorn and Manovskii (2008) argue that when the standard model is calibrated so as to match data on the cyclicality of real wages, the workers' bargaining weight is quite small. Thus it is of interest to explore the sensitivity of the results for the informational rents model to the NBS assumption of symmetric bargaining weights. This can be done by considering a weighted version of the Random Dictator mechanism, in which the worker is selected to choose the mechanism with probability $v$. Since the parameters are such that it is optimal for the worker to choose a pooling mechanism, while the employer's optimal mechanism claims the entire (state-contingent) surplus, any weighted Random Dictator mechanism is (privately) efficient ex post.

1. Balkenborg (2006) shows how Myerson's axioms can be modified so as to give a weighted version of the NBS. 


\subsection{Match surplus}

The match surplus depends on whether the idiosyncratic component of output is high or low, and it also depends on the aggregate state. Let $S_{s}^{\mathrm{L}}$ be the surplus when the idiosyncratic component is low, and the aggregate state is $s$, and similarly when the realization of $y$ is high; and let $y_{s}^{\mathrm{L}}=p_{s}+y^{\mathrm{L}}$, and $y_{s}^{\mathrm{H}}=p_{s}+y^{\mathrm{H}}$, with $\Delta y=y^{\mathrm{H}}-y^{\mathrm{L}}$.

Let $U$ denote the state-dependent continuation value of an unmatched worker, and let $G$ denote the joint continuation value of a matched worker-employer pair. When $y=y^{\mathrm{L}}$, the joint match values are determined by the following asset pricing equations ${ }^{2}$

$$
\begin{aligned}
& r G_{1}^{\mathrm{L}}=y_{1}^{\mathrm{L}}-\delta\left(G_{1}^{\mathrm{L}}-U_{1}\right)+\lambda_{1}\left(G_{2}^{\mathrm{L}}-G_{1}^{\mathrm{L}}\right) \\
& r G_{2}^{\mathrm{L}}=y_{2}^{\mathrm{L}}-\delta\left(G_{2}^{\mathrm{L}}-U_{2}\right)-\lambda_{2}\left(G_{2}^{\mathrm{L}}-G_{1}^{\mathrm{L}}\right)
\end{aligned}
$$

and similarly when $y=y^{\mathrm{H}}$. This specification rules out two interesting alternatives. First, the flow value of a match is the same for all workers. Nagypál (2005) shows that heterogeneity in workers' (private) evaluations of non-pecuniary job characteristics can substantially increase the volatility of unemployment. Second, there is no possibility of switching from low to high output, once the match has been made. Even in the absence of informational rents, this tends to increase unemployment volatility, by strengthening the incentive to create vacancies when a high-output match is more likely because the aggregate state is good. Costain and Reiter (2008) show that this vintage productivity effect can potentially explain the volatility of unemployment, but Brügemann (2005) shows that this effect is quite weak in the model considered in this paper.

It is assumed that there is free entry of employers, so that the continuation value of an unmatched employer is zero in all states. Thus the (state-dependent) match surplus $S$ is the difference between $G$ and $U$, and the match value equations can be rewritten as

$$
\begin{aligned}
& R\left(S_{1}^{\mathrm{L}}+U_{1}\right)=y_{1}^{\mathrm{L}}+\delta U_{1}+\lambda_{1}\left(S_{2}^{\mathrm{L}}-S_{1}^{\mathrm{L}}+\Delta U\right) \\
& R\left(S_{2}^{\mathrm{L}}+U_{2}\right)=y_{2}^{\mathrm{L}}+\delta U_{2}-\lambda_{2}\left(S_{2}^{\mathrm{L}}-S_{1}^{\mathrm{L}}+\Delta U\right),
\end{aligned}
$$

where $R=r+\delta$ and $\Delta U=U_{2}-U_{1}$. This implies

$$
S_{2}^{\mathrm{L}}-S_{1}^{\mathrm{L}}+\Delta U=\frac{y_{2}^{\mathrm{L}}-y_{1}^{\mathrm{L}}+\delta \Delta U}{R+\lambda_{1}+\lambda_{2}} .
$$

Substituting this in (2) gives

$$
\begin{aligned}
& R S_{1}^{\mathrm{L}}=y_{1}^{\mathrm{L}}-r U_{1}+\frac{\lambda_{1}\left(y_{2}^{\mathrm{L}}-y_{1}^{\mathrm{L}}+\delta \Delta U\right)}{R+\lambda_{1}+\lambda_{2}} \\
& R S_{2}^{\mathrm{L}}=y_{2}^{\mathrm{L}}-r U_{2}-\frac{\lambda_{2}\left(y_{2}^{\mathrm{L}}-y_{1}^{\mathrm{L}}+\delta \Delta U\right)}{R+\lambda_{1}+\lambda_{2}} .
\end{aligned}
$$

Using these equations, and the analogous equations for a high-output match, the effect of the aggregate state on the match surplus is given by

$$
S_{2}^{\mathrm{H}}-S_{1}^{\mathrm{H}}=S_{2}^{\mathrm{L}}-S_{1}^{\mathrm{L}}=\frac{p_{2}-p_{1}-\left(r+\lambda_{1}+\lambda_{2}\right) \Delta U}{R+\lambda_{1}+\lambda_{2}} .
$$

2. These and the subsequent equations implicitly assume that the continuation values change only when the aggregate state changes. In general, the values might also depend on other variables, and in particular, on the unemployment rate, which changes gradually after a change in the aggregate state. But in fact the continuation values depend only on the rate at which unemployed workers find jobs, and the rate at which vacancies are filled. In the Mortensen-Pissarides model, these rates are determined by how "tight" the labour market is (i.e. by the number of vacancies per unemployed worker), and the free entry condition ensures that the number of vacancies adjusts so that market tightness is constant over time, except that it jumps whenever the aggregate state changes. 
Thus, even if an unmatched worker has better prospects when the aggregate state is good, the match surplus might be lower, for a given output draw. On the other hand, there is a higher probability of drawing a high output value in the good aggregate state.

The effect of the output draw on the match surplus is given by

$$
\Delta S=S_{2}^{\mathrm{H}}-S_{2}^{\mathrm{L}}=S_{1}^{\mathrm{H}}-S_{1}^{\mathrm{L}}=\frac{\Delta y}{r+\delta} .
$$

\subsection{Unemployment continuation values}

The rate at which unemployed workers find new matches is $M\left(N_{\mathrm{U}}, N_{\mathrm{V}}\right) / N_{\mathrm{U}}=m(\theta)$, where $\theta=N_{\mathrm{V}} / N_{\mathrm{U}}$ represents market tightness, and $m(\theta)=M(1, \theta)$. The job-finding rate function $m(\theta)$ is assumed to be increasing, and strictly concave, with $m(0)=0$.

When a match is made, the worker is selected to make an offer with probability $v$. In the case of a pooling offer, the worker gets the low-output surplus, and the employer gets an informational rent if the realized output value is high. If the worker makes a screening offer, the employer gets nothing, and the worker gets the high-output surplus with probability $\tau_{s}$. It will be assumed that the parameters are such that pooling offers are always optimal, but it is necessary to allow for the possibility of screening offers in order to characterize the relevant parameter restrictions. If the employer is selected to make an offer, the worker gets the reservation level $U$ and the employer gets the whole surplus. So an unmatched worker's continuation values are determined by the asset pricing equations

$$
\begin{aligned}
& r U_{1}=y_{0}+m\left(\theta_{1}\right) v\left(\left(1-\chi_{1}\right) S_{1}^{\mathrm{L}}+\chi_{1} \tau_{1}\left(S_{1}^{\mathrm{L}}+\Delta S\right)\right)+\lambda_{1}\left(U_{2}-U_{1}\right) \\
& r U_{2}=y_{0}+m\left(\theta_{2}\right) v\left(\left(1-\chi_{2}\right) S_{2}^{\mathrm{L}}+\chi_{2} \tau_{2}\left(S_{2}^{\mathrm{L}}+\Delta S\right)\right)-\lambda_{2}\left(U_{2}-U_{1}\right),
\end{aligned}
$$

where $\chi_{s}$ is the probability that the worker makes a screening offer in state $s$.

\subsection{Vacancy creation}

Employers post new vacancies to the point where the net profit from doing so is zero. When a match is made in state $s$, the employer's continuation value is

$$
\begin{aligned}
J_{s} & =\tau_{s}(1-v) S_{s}^{\mathrm{H}}+\tau_{s} v\left(1-\chi_{s}\right) \Delta S+\left(1-\tau_{s}\right)(1-v) S_{s}^{\mathrm{L}}+\left(1-\tau_{s}\right) v \times 0 \\
& =(1-v) S_{1}^{\mathrm{L}}+\tau_{s}\left(1-v \chi_{s}\right) \Delta S .
\end{aligned}
$$

Thus the zero-profit conditions implied by free entry are

$$
0=-c+\frac{m\left(\theta_{s}\right)}{\theta_{s}}\left((1-v) S_{s}^{\mathrm{L}}+\tau_{s}\left(1-v \chi_{s}\right) \Delta S\right)
$$

for $s \in\{1,2\}$, where $c$ is the flow cost of maintaining a vacancy.

\subsection{Solution}

The model can be solved as follows. Let $d_{s}=\theta_{s} / m\left(\theta_{s}\right)$ denote the expected duration of a vacancy. For given values of $d_{1}$ and $d_{2}$, the free entry conditions determine the low-state surplus values:

$$
S_{s}^{\mathrm{L}}=\frac{c x_{s}}{1-v}
$$


where

$$
\begin{aligned}
& x_{s}=d_{s}-\left(1-v \chi_{s}\right) \rho_{s} \\
& \rho_{s}=\frac{\tau_{s} \Delta y}{c R}
\end{aligned}
$$

for $s \in\{1,2\}$. Rearrange equation (2) as

$$
\begin{aligned}
& r U_{1}=y_{1}^{\mathrm{L}}+\frac{\lambda_{1}\left(\mathrm{y}_{2}^{\mathrm{L}}-\mathrm{y}_{1}^{\mathrm{L}}\right)}{r+\lambda_{1}+\lambda_{2}}-(\delta+r) \frac{c x_{1}}{1-v}-\frac{\lambda_{1} \delta c\left(x_{2}-x_{1}\right)}{(1-v)\left(r+\lambda_{1}+\lambda_{2}\right)} \\
& r U_{2}=y_{2}^{\mathrm{L}}-\frac{\lambda_{2}\left(\mathrm{y}_{2}^{\mathrm{L}}-\mathrm{y}_{1}^{\mathrm{L}}\right)}{r+\lambda_{1}+\lambda_{2}}-(\delta+r) \frac{c x_{2}}{1-v}+\frac{\lambda_{2} \delta c\left(x_{2}-x_{1}\right)}{(1-v)\left(r+\lambda_{1}+\lambda_{2}\right)} .
\end{aligned}
$$

Substitute (10) in (7) to get

$$
\begin{aligned}
& \left(r+\lambda_{1}\right) U_{1}-\lambda_{1} U_{2}=y_{0}+m\left(\theta_{1}\right) \frac{v c X_{1}}{1-v} \\
& \left(r+\lambda_{2}\right) U_{2}-\lambda_{2} U_{1}=y_{0}+m\left(\theta_{2}\right) \frac{v c X_{2}}{1-v}
\end{aligned}
$$

where

$$
X_{s}=\left(1-\chi_{s}\left(1-\tau_{s}\right)\right) x_{s}+\chi_{s}(1-v) \rho_{s}
$$

with $X_{s}=x_{s}=d_{s}-\rho_{s}$ in the pooling case.

Since $m(\theta)$ is strictly concave, with $m(0)=0$, the ratio $m(\theta) / \theta$ is strictly decreasing, so the function $d=\theta / m(\theta)$ has an inverse, $\theta=H(d)$. Using equations (7) and (13) to eliminate $U_{1}$ and $U_{2}$, and making the substitution $m\left(\theta_{s}\right)=H\left(d_{s}\right) / d_{s}$ to eliminate $\theta$, gives the following equations determining $d_{1}$ and $d_{2}$

$$
\begin{aligned}
& \Psi_{1}(d, \chi)=Z_{1}-X_{1} \frac{\nu H\left(d_{1}\right)}{d_{1}}-R x_{1}+\lambda_{1}\left(x_{2}-x_{1}\right)=0 \\
& \Psi_{2}(d, \chi)=Z_{2}-X_{2} \frac{\nu H\left(d_{2}\right)}{d_{2}}-R x_{2}+\lambda_{2}\left(x_{1}-x_{2}\right)=0
\end{aligned}
$$

where

$$
Z_{s}=\frac{(1-v)\left(y_{s}^{\mathrm{L}}-y_{0}\right)}{c}, s \in\{1,2\}
$$

\subsection{Optimality of pooling offers}

It will be assumed that the parameters are such that when a match is made and the worker is selected to make an offer, it is optimal to demand the low surplus, rather than demanding the high surplus at the risk of destroying the match.

A pooling offer is optimal in state $s$ if and only if the equilibrium surplus values satisfy the following condition:

$$
S_{s}^{\mathrm{L}} \geq \tau_{s} S_{s}^{\mathrm{H}}=\tau_{s}\left(S_{s}^{\mathrm{L}}+\frac{\Delta y}{R}\right) .
$$

Using the free entry conditions, this can be stated as

$$
x_{s} \geq \bar{x}_{s}
$$


where

$$
\bar{x}_{s}=\frac{1-v}{1-\tau_{s}} \rho_{s} .
$$

Similarly, a screening offer is optimal in state $s$ if and only if

$$
S_{s}^{\mathrm{L}} \leq \tau_{s}\left(S_{s}^{\mathrm{L}}+\frac{\Delta y}{R}\right)
$$

which can be stated as

$$
x_{s} \leq \bar{x}_{s}
$$

It will be assumed that it is optimal to make pooling offers with probability one (meaning that $\chi_{s}=0$ ). This no-screening condition can be expressed in terms of the expected vacancy duration as

$$
d_{s} \geq \bar{\rho}_{s},
$$

where

$$
\bar{\rho}_{s}=\left(1+\frac{1-v}{1-\tau_{s}}\right) \rho_{s} .
$$

\section{EXISTENCE AND UNIQUENESS OF EQUILIBRIUM}

It is assumed that the function $\theta=H(d)$ is convex, with $H(0)=0 .{ }^{3}$ Under this assumption, it will be shown that an equilibrium with informational rents exists, and that it is unique.

Proposition 1. If the function $\theta=H(d)$ is convex, and if $H(0)=0$, then there is a unique vector $d^{*}=\left(d_{1}^{*}, d_{2}^{*}\right)$ such that $\Psi_{1}\left(d^{*}, 0\right)=\Psi_{2}\left(d^{*}, 0\right)=0$.

The proof uses the following result.

Lemma 1. Suppose $H$ is a twice differentiable function, with $H(0)=0, H^{\prime}(x)>0$ and $H^{\prime \prime}(x)>0$, for $x>a>0$. Define the function $h$, on the domain $[a, \infty)$, as

$$
h(x)=\left(\frac{a}{x}-1\right) H(x) .
$$

Then $h^{\prime}(x)<0$ and $h^{\prime \prime}(x)<0$.

3. This assumption holds in the Cobb-Douglas case. The condition $H(0)=0$ means that the expected vacancy duration shrinks to zero as the number of vacancies per unemployed worker shrinks to zero. Although this is a reasonable condition, it effectively rules out any constant returns CES matching technology except for the CobbDouglas. Indeed if the matching function is defined by $(M / \mu)^{\varrho}=\alpha U^{\varrho}+(1-\alpha) V^{\varrho}$, then a positive value of $\varrho$ is ruled out because it implies that matches can be made even if there are no vacancies. On the other hand, a negative value of $\varrho$ is ruled out by the condition that $\theta / m(\theta)$ shrinks to zero as $\theta$ decreases to zero. This is a case in which local behaviour around $\theta=0$ has global implications because the CES parametric family is inflexible. It is not difficult to stitch together a Cobb-Douglas and a CES with negative $\varrho$, so that the function is Cobb-Douglas near zero, with $H(0)=0$. Then if $\varrho<-1$, the function $H(d)$ is not convex. 
Proof. The first and second derivatives of $\mathrm{h}$ are as follows

$$
\begin{aligned}
h^{\prime}(x) & =\left(\frac{a}{x}-1\right) H^{\prime}(x)-\frac{a}{x^{2}} H(x) \\
h^{\prime \prime}(x) & =\left(\frac{a}{x}-1\right) H^{\prime \prime}(x)-\frac{2 a}{x^{2}} H^{\prime}(x)+\frac{2 a}{x^{3}} H(x) \\
& =\left(\frac{a}{x}-1\right) H^{\prime \prime}(x)+\frac{2 a}{x^{3}}\left(H(x)-x H^{\prime}(x)\right) .
\end{aligned}
$$

Since $x \geq a$, and $H^{\prime}(x)>0$, it is clear that $h$ is decreasing. Any convex (differentiable) function $H$ that passes through the origin has the property that $x H^{\prime}(x) \geq H(x)$. Thus $h^{\prime \prime}(x) \leq 0$. $\|$

Proof of Proposition 1. Define $\psi(d)=\left(\Psi_{1}(d, 0), \Psi_{2}(d, 0)\right)$. First it will be shown that $\psi(d)=0$ implies $d>\rho$. Indeed if $d_{1} \leq \rho_{1}$ and $d_{2} \geq \rho_{2}$ then $\psi_{1}(d)>0$; and if $d_{1} \geq \rho_{1}$ and $d_{2} \leq \rho_{2}$ then $\psi_{2}(d)>0$. If $d \leq \rho$, write $\psi(d)$ as

$$
\begin{aligned}
& \psi_{1}(d)=Z_{1}+\left(\rho_{1}-d_{1}\right) v \frac{H\left(d_{1}\right)}{d_{1}}-R\left(d_{1}-\rho_{1}\right)+\lambda_{1}\left[\left(d_{2}-\rho_{2}\right)-\left(d_{1}-\rho_{1}\right)\right] \\
& \psi_{2}(d)=Z_{2}+\left(\rho_{2}-d_{2}\right) v \frac{H\left(d_{2}\right)}{d_{2}}-R\left(d_{2}-\rho_{2}\right)+\lambda_{2}\left[\left(d_{2}-\rho_{2}\right)-\left(d_{1}-\rho_{1}\right)\right] .
\end{aligned}
$$

These equations show that either $\psi_{1}(d)$ or $\psi_{2}(d)$ is a sum of positive terms: the first three terms are positive in both equations, and if the last term is negative in one equation, it is positive in the other. Thus $\psi(d) \neq 0$ if $d \leq \rho$.

Next it will be shown that a solution exists. Note that $\psi(\rho)=Z>0$. Define $b$ as the solution of the linear equations obtained by setting $H=0$. Then

$$
b_{s}=\rho_{s}+\frac{\bar{Z}_{s}}{R}, \quad s=1,2,
$$

where

$$
\begin{aligned}
& \bar{Z}_{1}=\frac{\left(R+\lambda_{2}\right) Z_{1}+\lambda_{1} Z_{2}}{R+\lambda_{1}+\lambda_{2}} \\
& \bar{Z}_{2}=\frac{\left(R+\lambda_{1}\right) Z_{2}+\lambda_{2} Z_{1}}{R+\lambda_{1}+\lambda_{2}} .
\end{aligned}
$$

Thus $b>\rho$ and $\psi(b)<0$.

Since $\psi_{1}$ is increasing and unbounded in $d_{2}$, and decreasing and unbounded in $d_{1}$, the equation $\psi_{1}(d)=0$ can be solved to obtain $d_{2}$ as an increasing function of $d_{1}$. Write this as $d_{2}=\Upsilon_{1}\left(d_{1}\right)$. Similarly, the equation $\psi_{2}(d)=0$ can be solved to obtain $d_{2}$ as an increasing function of $d_{1}$ : write this as $d_{2}=\Upsilon_{2}\left(d_{1}\right)$. Define the function $\Upsilon_{0}(x)=\Upsilon_{2}(x)-\Upsilon_{1}(x)$. Since $\psi_{1}\left(\rho_{1}, \Upsilon_{1}\left(\rho_{1}\right)\right)=0$, and $\psi_{1}\left(\rho_{1}, \rho_{2}\right)>0$, and $\psi_{1}$ is increasing in $d_{2}$, it follows that $\Upsilon_{1}\left(\rho_{1}\right)<\rho_{2}$. Also, since $\psi_{2}\left(\rho_{1}, \Upsilon_{2}\left(\rho_{1}\right)\right)=0$, and $\psi_{2}\left(\rho_{1}, \rho_{2}\right)>0$, and $\psi_{2}$ is decreasing in $d_{2}$, it follows that $\Upsilon_{2}\left(\rho_{1}\right)>\rho_{2}$. Therefore $\Upsilon_{0}\left(\rho_{1}\right)$ is positive. By a similar argument, $\Upsilon_{0}\left(b_{1}\right)$ is negative. Also, $\Upsilon_{0}$ is continuous (since $\psi_{1}$ is linear in $d_{2}$ and $\psi_{2}$ is linear in $d_{1}$ ). So by the intermediate value theorem $\Upsilon_{2}\left(x^{*}\right)=\Upsilon_{1}\left(x^{*}\right)$ for some $x^{*} \in\left(\rho_{1}, b_{1}\right)$. This means that $\psi\left(x^{*}, \Upsilon_{1}\left(x^{*}\right)\right)=0$, showing that a solution $d^{*}=\left(x^{*}, \Upsilon_{1}\left(x^{*}\right)\right)$ exists (with $\left.d^{*}>\rho\right)$.

To show uniqueness, define the function $g(z)=\psi(\rho+z)$. Then $g(0)>0, g_{1}$ is increasing in $z_{2}$ and $g_{2}$ is increasing in $z_{1}$, and $g_{1}$ and $g_{2}$ are concave by Lemma 1 . Therefore, by Theorem 1 in Kennan (2001), $g$ has at most one positive root, meaning that $\psi$ has at most one root 
above $\rho$. Since it has already been shown that $\psi$ does have a root above $\rho$, and no roots anywhere else, this completes the proof. \|

Since $\rho_{s}=0$ for $\tau_{s}=0$, Proposition 1 implies that a unique equilibrium satisfying the no-screening conditions exists if $\tau_{1}$ and $\tau_{2}$ are small enough. Conversely, the no-screening condition fails as $\tau_{s}$ approaches 1 (as of course it should). Also, the condition necessarily holds if the expected cost of filling a vacancy is high enough. The choice between pooling and screening depends on how big the difference is between the good idiosyncratic draw and the bad draw, relative to the surplus associated with the bad draw. A screening offer risks losing the low surplus, in exchange for a chance of getting the high surplus. When the expected cost of filling a vacancy is high, the free entry condition implies that the surplus associated with a filled vacancy is high. The effect of this is to increase the opportunity cost of screening, without changing the benefit, so pooling becomes more attractive.

The main theoretical result is Theorem 1, which characterizes a set of parameter values for which an equilibrium exists, and shows that if the parameters lie in this set, the equilibrium is unique.

Theorem 1. If $H(d)$ is a convex function, with $H(0)=0$, and if $\Psi(\bar{\rho}, 1)>0$, then a unique equilibrium exists.

Proof. By Proposition 1, there is a unique vector $d^{*}$ such that $\psi\left(d^{*}\right)=0$. Since $\psi(\bar{\rho})>$ 0 and $\psi(b)<0$, the argument in the proof of Proposition 1 can be used to show that $\psi$ has a root in the rectangle $[\bar{\rho}, b]$, and since there is only one root above $\rho$, this root is $d^{*}$. Pooling offers are optimal because $d^{*} \geq \bar{\rho} d^{*} \geq$. Therefore $d^{*}$ is the unique pooling equilibrium.

Next it will be shown that if there is an equilibrium at $(\tilde{d}, \tilde{\chi})$ with screening in either state there is a contradiction. First suppose $\lambda_{s}=0$. If $\tilde{\chi}_{s}>0$ then $\tilde{d}_{s} \leq \bar{\rho}_{s}$ and $\tilde{x}_{s} \leq \bar{x}_{s}$ and $\tilde{X}_{s} \leq \bar{x}_{s}$, which implies $0=\Psi_{s}(\tilde{d}, \tilde{\chi}) \geq \Psi_{s}(\bar{\rho}, 1)$, contradicting the assumption that $\Psi(\bar{\rho}, 1)>0$. So if $\lambda_{s}=0$ then $\tilde{\chi}_{s}=0$.

Now suppose $(\tilde{d}, \tilde{\chi})$ has screening in one state and pooling in the other. Say there is screening in state 2. Then $\tilde{\chi}_{2}>0$ and $\tilde{d}_{2} \leq \bar{\rho}_{2}$ and $\tilde{x}_{2} \leq \bar{x}_{2}$ and $\tilde{X}_{2} \leq \bar{x}_{2}$, while pooling in state 1 implies $\tilde{\chi}_{1}=0$ and $\tilde{x}_{1} \geq \bar{x}_{1}$ and $\tilde{X}_{1} \geq \bar{x}_{1}$. Thus

$$
\begin{aligned}
0 & =\Psi_{2}(\tilde{d}, \chi)=Z_{2}-\tilde{X}_{2} \frac{\nu H\left(\tilde{d}_{2}\right)}{\tilde{d}_{2}}-R \tilde{x}_{2}+\lambda_{2}\left(\tilde{x}_{1}-\tilde{x}_{2}\right) \\
& \geq Z_{2}-\bar{x}_{2} \frac{\nu H\left(\bar{\rho}_{2}\right)}{\bar{\rho}_{2}}-R \bar{x}_{2}+\lambda_{2}\left(\bar{x}_{1}-\bar{x}_{2}\right) \\
& =\Psi_{2}(\bar{\rho}, 0),
\end{aligned}
$$

again contradicting the assumption that $\Psi(\bar{\rho}, 1)>0$.

Finally, if $\tilde{d}$ has screening in both states, then $\lambda>0$ (by the argument above), and $\tilde{d} \leq \bar{\rho}$ and $\tilde{x} \leq \bar{x}$ and $\tilde{X} \leq \bar{x}$. This implies

$$
\begin{aligned}
0 & =\lambda_{2} \Psi_{1}(\tilde{d}, \tilde{\chi})+\lambda_{1} \Psi_{2}(\tilde{d}, \tilde{\chi}) \\
& =\lambda_{2}\left(Z_{1}-\tilde{X}_{1} \frac{\nu H\left(\tilde{d}_{1}\right)}{\tilde{d}_{1}}-R \tilde{x}_{1}\right)+\lambda_{1}\left(Z_{2}-\tilde{X}_{2} \frac{\nu H\left(\tilde{d}_{2}\right)}{\tilde{d}_{2}}-R \tilde{x}_{2}\right) \\
& \geq \lambda_{2}\left(Z_{1}-\bar{x}_{1} \frac{\nu H\left(\bar{\rho}_{1}\right)}{\bar{\rho}_{1}}-R \bar{x}_{1}\right)+\lambda_{1}\left(Z_{2}-\bar{x}_{2} \frac{\nu H\left(\bar{\rho}_{2}\right)}{\bar{\rho}_{2}}-R \bar{x}_{2}\right) \\
& =\lambda_{2} \Psi_{1}(\bar{\rho}, 0)+\lambda_{1} \Psi_{2}(\bar{\rho}, 0)>0,
\end{aligned}
$$


a contradiction. Thus if $\Psi(\bar{\rho}, 1)>0$ there is no equilibrium in which screening offers are made with positive probability. \|

The condition $\Psi(\bar{\rho}, 1)>0$ can be interpreted as an upper bound on the potential gains from screening offers, relative to the opportunity cost, where the gains are proportional to $\Delta y$. The following result states the condition in terms of a threshold value for $\Delta y$.

Proposition 2. If $H(d)$ is a convex function, with $H(0)=0$, there is a number $\delta_{y}>0$ such that a unique equilibrium exists if $\Delta y<\delta_{y}$.

Proof. The condition $\Psi(\bar{\rho}, 1)>0$ can be written as

$$
\begin{aligned}
& \frac{\psi_{1}(\bar{\rho})}{1-v}=\frac{Z_{1}}{1-v}-\left(\frac{1-\tau_{1}}{1-\tau_{1}+1-v}\right) v H\left(\bar{\rho}_{1}\right)-\frac{R \rho_{1}}{1-\tau_{1}}+\lambda_{1}\left(\frac{\rho_{2}}{1-\tau_{2}}-\frac{\rho_{1}}{1-\tau_{1}}\right)>0 \\
& \frac{\psi_{2}(\bar{\rho})}{1-v}=\frac{Z_{2}}{1-v}-\left(\frac{1-\tau_{2}}{1-\tau_{2}+1-v}\right) v H\left(\bar{\rho}_{2}\right)-\frac{R \rho_{2}}{1-\tau_{2}}+\lambda_{2}\left(\frac{\rho_{1}}{1-\tau_{1}}-\frac{\rho_{2}}{1-\tau_{2}}\right)>0 .
\end{aligned}
$$

Note that $\bar{\rho}_{s}$ is a positive multiple of $\Delta y$, and $H$ is an increasing convex function that passes through the origin. Also, if $\tau_{2}>\tau_{1}$ then $\psi_{2}$ is unbounded below, and if $\tau_{1}>\tau_{2}$ then $\psi_{1}$ is unbounded below. So $\min \left\{\psi_{1}(\bar{\rho}), \psi_{2}(\bar{\rho})\right\}$, considered as a function of $\Delta y$, is concave, positive at the origin, and unbounded below, so it has a unique positive root, $\delta_{y}$. Then $\Psi(\bar{\rho}, 1)>0$ if $\Delta y<\delta_{y}$.

\section{THE EFFECTS OF INFORMATIONAL RENTS}

Suppose that there are no transitions, and that the wage rate is fixed, as in Hall (2005). Then the free entry condition is

$$
c d=\frac{y^{\mathrm{L}}-w+\tau \Delta y}{R} .
$$

The right side of this equation is the capital gain from a filled vacancy, and the left side is the flow cost of maintaining the vacancy, multiplied by the expected vacancy duration. A higher productivity level, with a fixed wage, is offset in equilibrium by an increase in duration. If the profit flow is small (because the wage is high), a small productivity change implies a large proportional change in profits, and therefore a large proportional change in the rate at which vacancies are filled, which implies a large change in the unemployment rate.

The following lemma characterizes the wage as a nested weighted average of the productivity levels while employed $(y)$ and while unemployed $\left(y_{0}\right)$. This characterization applies to the standard Mortensen-Pissarides model, and in the informational rents model, the wage is determined in exactly the same way, assuming the low realization of the productivity shock $\left(y^{\mathrm{L}}\right)$. Let $\phi=m(\theta)$ be the job-finding rate, and define $w_{0}$ as the wage such that the worker's share of the flow surplus is $v$ :

$$
w_{0}=v y^{\mathrm{L}}+(1-v) y_{0}
$$

Lemma 2. If the aggregate state is permanent, the equilibrium wage is given by

$$
w=\Omega y^{L}+(1-\Omega) w_{0} .
$$


where

$$
\frac{1}{\Omega}=1+\frac{R}{v \phi}
$$

Proof. From equation (7), the continuation value of an unemployed worker is

$$
r U=y_{0}+\phi v S^{\mathrm{L}} .
$$

Equation (4) gives the surplus as

$$
R S^{\mathrm{L}}=y^{\mathrm{L}}-r U
$$

Solving these equations for $U$ and $S^{\mathrm{L}}$ yields

$$
v S^{\mathrm{L}}=\frac{y^{\mathrm{L}}-y_{0}}{\frac{R}{v}+\phi}
$$

and

$$
r U=\Omega y^{\mathrm{L}}+(1-\Omega) y_{0} .
$$

The continuation value of an employed worker is $E=U+v S^{\mathrm{L}}$. The wage that delivers this value satisfies the asset pricing equation

$$
r E=w-\delta(E-U) .
$$

Thus the wage is given by

$$
\begin{aligned}
w & =(r+\delta) E-\delta U \\
& =r U+(r+\delta) v S^{\mathrm{L}} \\
& =\Omega y^{\mathrm{L}}+(1-\Omega) y_{0}+(1-\Omega) v\left(y^{\mathrm{L}}-y_{0}\right) \\
& =\Omega y^{\mathrm{L}}+(1-\Omega) w_{0},
\end{aligned}
$$

which proves the result.

The point of this lemma is that even if the bargaining process treats the worker and the employer symmetrically, so that $w_{0}$ is at the midpoint of the interval $\left[y_{0}, y^{\mathrm{L}}\right]$, the wage is nevertheless close to $y^{\mathrm{L}}$, because it is a weighted average of the midpoint and $y^{\mathrm{L}}$, and the weight on $y^{\mathrm{L}}$ is close to one when the job-finding rate is high.

Using Lemma 2, the free entry condition can be written as

$$
c d=\frac{(1-v)\left(y^{\mathrm{L}}-y_{0}\right)}{\nu \phi+R}+\rho .
$$

The result for the standard model (with $\tau \Delta y=0$ ) differs from the fixed wage result in two respects. First, if the job-finding rate is held constant, a large proportional change in $d$ requires a large proportional change in the flow surplus from employment (rather than in the flow profit). This means that small productivity shocks do not cause large unemployment movements unless the flow surplus is small, as in Hagedorn and Manovskii (2008). Second, this exaggerates the relationship between productivity and unemployment, because the job-finding rate does not 
in fact stay constant when $d$ increases. An increase in $d$ implies an increase in $\phi$, and this dampens the relationship between productivity and unemployment: workers receive a larger share of the flow surplus when an increase in the job-finding rate increases the value of being unemployed, and this diminishes the incentive to create vacancies.

Informational rents affect unemployment in much the same way as fixed wages, because small productivity changes that are observed privately by employers do not affect wages. The wage is close to the low productivity level, for standard parameter values, so the profit flow $y^{\mathrm{L}}-w$ is small in equation (42). Since $\tau \Delta y$ is also small (in the sense that pooling offers are optimal), changes in $\tau \Delta y$ therefore give rise to large proportional changes in profits, and in the unemployment rate.

\subsection{The Cobb-Douglas case}

The equilibrium relationships between productivity, informational rents and the unemployment rate can be characterized more explicitly in the case of a constant-returns Cobb-Douglas matching function, $M=\mu U^{\alpha} V^{1-\alpha}$, with $m(\theta)=\mu \theta^{1-\alpha}$. In this case the equilibrium conditions (15) can be stated as

$$
\begin{aligned}
& v \zeta_{1}=\left(v \phi_{1}+R\right) \xi_{1}+\lambda_{1}\left(\xi_{1}-\xi_{2}\right) \\
& v \zeta_{2}=\left(v \phi_{2}+R\right) \xi_{2}+\lambda_{2}\left(\xi_{2}-\xi_{1}\right),
\end{aligned}
$$

where $\phi_{s}=m\left(\theta_{s}\right)$, and

$$
\begin{aligned}
& \xi_{s}=\left(\phi_{s}\right)^{\frac{\alpha}{1-\alpha}}-\frac{\mu^{\frac{1}{1-\alpha}}}{c} \rho_{s} \\
& \zeta_{s}=\frac{\mu^{\frac{1}{1-\alpha}}}{c} \frac{1-v}{v}\left(y_{s}^{\mathrm{L}}-y_{0}\right) .
\end{aligned}
$$

Thus, as Shimer (2005) noted, the parameters $c$ and $\mu$ enter only through the ratio $\mu_{0}=$ $\frac{1}{c} \mu^{1 /(1-\alpha)}$.

If the aggregate state is permanent, equation (43) reduces to (two copies of) the following equation:

$$
\zeta=\left(\phi^{\alpha /(1-\alpha)}-\mu_{0} \rho\right)\left(\phi+\frac{R}{v}\right),
$$

where

$$
\zeta=\frac{1-v}{v} \mu_{0}\left(y^{\mathrm{L}}-y_{0}\right) .
$$

The effect of productivity variation with a square-root matching function $(\alpha=1 / 2)$ and no informational rents is illustrated in Figure 1, which plots the quadratic function on the right side of equation (45) against the constant on the left side, with $\rho$ set to zero. Productivity changes move the horizontal line up and down in this figure, and the equilibrium job-finding rate adjusts along the quadratic curve. For standard parameter values, this curve is steep at the baseline equilibrium, and small productivity differences therefore have little effect on the job-finding rate. ${ }^{4}$

4. In this figure, $\mu_{0}$ is chosen so that the job-finding rate in the good steady state matches the data. Using the baseline parameters from Table 1 , with $\Delta y=0$ and $y=1.03$, setting $\mu_{0}=1360 / 21$ implies $\phi_{2}=6$. The horizontal lines are drawn for $y=1$ and $y=1.03$. 


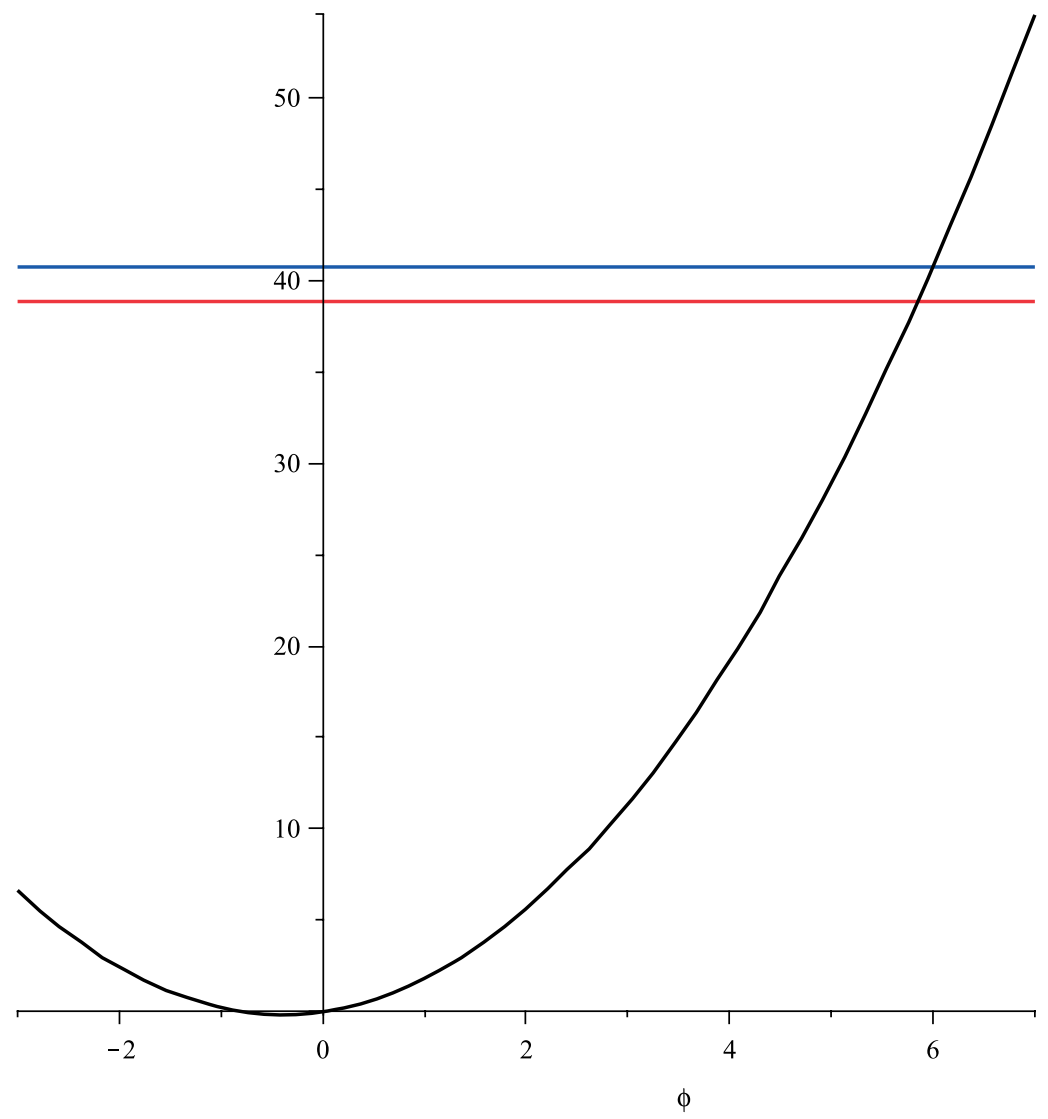

FIGURE 1

Relationship between productivity and the job-finding rate, basic model

The elasticity of the job-finding rate with respect to productivity with no informational rents is

$$
\frac{\partial \log (\phi)}{\partial \log (y)}=\frac{\frac{\partial \log (\zeta)}{\partial \log (y)}}{\frac{\partial \log (\zeta)}{\partial \log (\phi)}}=\frac{y}{y-y_{0}} \frac{1}{\frac{1}{\frac{1}{\alpha}-1}+\frac{1}{1+\frac{R}{v} \frac{1}{\phi}}}
$$

For standard parameter values, this elasticity is not large unless the match surplus is small. ${ }^{5}$

The effect of informational rents is shown in Figure 2. When $\rho$ is positive, the quadratic curve shifts to the right (in the relevant region), and a comparison of the two curves shows

5. It is worth noting that the elasticity can be made arbitrarily large, even if the flow surplus is not small, by assigning very small values for the parameters $\alpha$ and $v$. For example, if $\alpha=v=0.01$, with $\phi=6, y^{\mathrm{L}}=1, y_{0}=0.4$, and $R=0.4$, as in Table 1 , the elasticity is $759 / 64=11.86$. The reason for this is that the elasticity of the job-finding rate with respect to productivity depends on the supply elasticity of new matches. If the marginal cost of new matches is almost constant, then a small increase in the value of new matches leads to a large increase in matches, and thus a large increase in the job-finding rate. When $\alpha$ is close to zero, and $v=\alpha$ so that the equilibrium is efficient, the marginal cost of new matches is almost constant because the matching function is almost linear in vacancies, and the efficient response to changes in match productivity is therefore very elastic. 


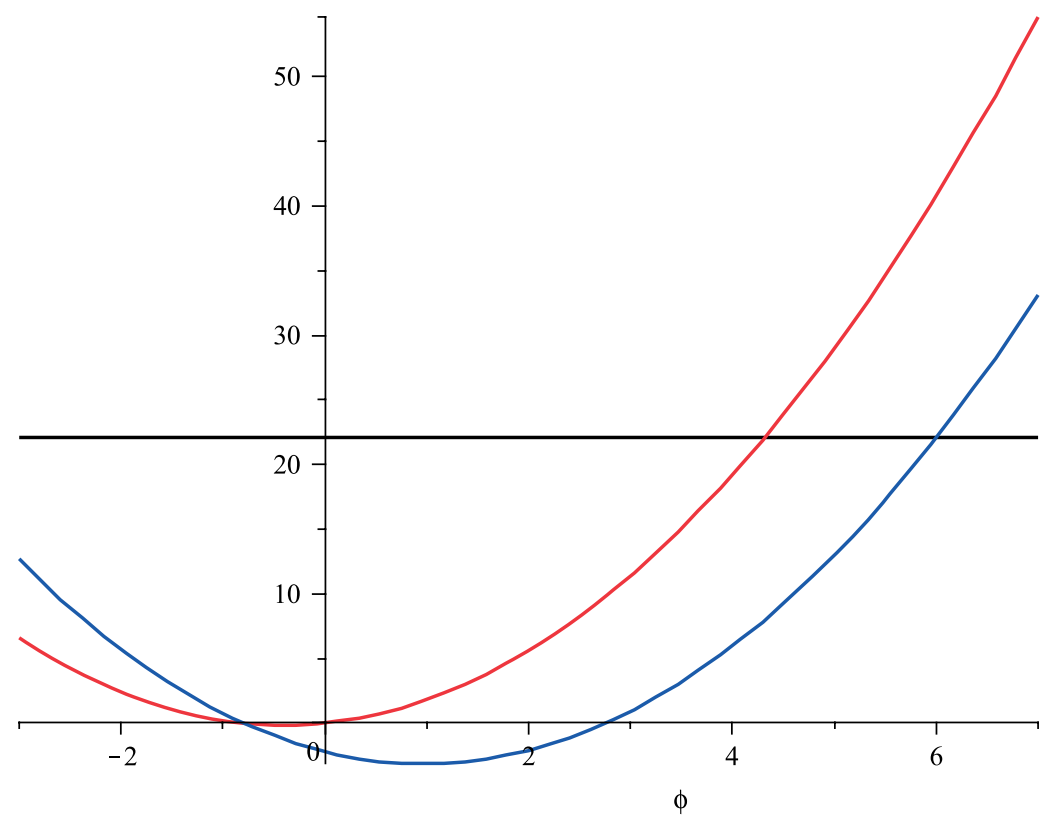

FIGURE 2

Informational rents and the relationship between productivity and the job-finding rate

that a small informational rent has a large effect on the equilibrium job-finding rate. On the other hand, the effect of (publicly observed) productivity movements remains small. ${ }^{6}$

\section{WAGES}

Pissarides (forthcoming) has recently argued that wage stickiness is not the answer to the unemployment volatility puzzle, simply because wages are not in fact sticky: the wages of jobchangers vary procyclically, and there is also evidence (due to Beaudry and DiNardo, 1991) that wages in continuing matches depend on labour market conditions at the time the match was made. In this paper wages are sticky in the sense that they do not respond directly to improvements in the distribution of the idiosyncratic component of match productivity, and the informational rent associated with this stickiness provides an incentive to create vacancies. But this does not imply that wages are acyclical: the informational rent has an indirect effect on wages by increasing the job-finding rate, and thereby increasing the continuation value of an unemployed worker. When the aggregate state is permanent $\left(\lambda_{1}=\lambda_{2}=0\right)$ the magnitude of this effect is given by Lemma 2. More generally, the cyclical variation of wages can be analysed using a matrix version of Lemma 2. Suppose $\tilde{U}$ is the continuation value of an employed worker, starting from the end of the job (that is, assuming that wages are zero on the present job from now on). Then

$$
\left(\begin{array}{cc}
R+\lambda_{1} & -\lambda_{1} \\
-\lambda_{2} & R+\lambda_{2}
\end{array}\right)\left(\begin{array}{c}
\tilde{U}_{1} \\
\tilde{U}_{2}
\end{array}\right)=\delta\left(\begin{array}{l}
U_{1} \\
U_{2}
\end{array}\right) .
$$

This can be written in matrix form as $\Gamma \tilde{U}=\delta U$.

6. Here $\mu_{0}$ is again chosen so that the job-finding rate in the good steady state matches the data. Using the baseline parameters from Table 1 , with $\tau_{2} \Delta y=3 / 100$ and $y=1$, setting $\mu_{0}=1360 / 37$ implies $\phi_{2}=6$. 
A job that starts in state $s$ is worth $U_{s}+v S_{s}^{\mathrm{L}}$ to the worker. This is delivered in two parts:

$$
U+v S^{\mathrm{L}}=W+\tilde{U} .
$$

Thus, the present value of wages is

$$
\begin{aligned}
W & =v S^{\mathrm{L}}+U-\tilde{U} \\
& =v S^{\mathrm{L}}+\left(I-\delta \Gamma^{-1}\right) U,
\end{aligned}
$$

where $W$ is the vector $\left(W_{1}, W_{2}\right)^{\prime}$.

The surplus in a match with a low idiosyncratic component is given by equation (2):

$$
\Gamma\left(S^{\mathrm{L}}+U\right)=y^{\mathrm{L}}+\delta U .
$$

The continuation value of an unemployed worker is given by equation (7):

$$
(\Gamma-\delta I) U=y_{0}+\nu \Phi S^{\mathrm{L}},
$$

where $\Phi$ is a diagonal matrix with elements $\phi_{1}$ and $\phi_{1}$. Combining these equations gives

$$
\begin{aligned}
S^{\mathrm{L}} & =(\Gamma+\nu \Phi)^{-1}\left(y^{\mathrm{L}}-y_{0}\right) \\
U & =(\Gamma-\delta I)^{-1}\left(y_{0}+\nu \Phi(\Gamma+v \Phi)^{-1}\left(y^{\mathrm{L}}-y_{0}\right)\right) .
\end{aligned}
$$

Thus the present value of wages is

$$
\begin{aligned}
W & =v S^{\mathrm{L}}+\left(I-\delta \Gamma^{-1}\right)(\Gamma-\delta I)^{-1}\left(y_{0}+v \Phi S^{\mathrm{L}}\right) \\
& =\Gamma^{-1} y_{0}+\left(I+\Gamma^{-1} \Phi\right) v S^{\mathrm{L}} \\
& =\Gamma^{-1} y_{0}+v\left(I+\Gamma^{-1} \Phi\right)(\Gamma+v \Phi)^{-1}\left(y^{\mathrm{L}}-y_{0}\right)
\end{aligned}
$$

The matrix analogue of Lemma 2 is

$$
\begin{aligned}
\Gamma W & =y_{0}+v(\Gamma+\Phi)(\Gamma+v \Phi)^{-1}\left(y^{\mathrm{L}}-y_{0}\right) \\
& =v(\Gamma+\Phi)(\Gamma+v \Phi)^{-1} y^{\mathrm{L}}+\Gamma(\Gamma+v \Phi)^{-1}(1-v) y_{0} .
\end{aligned}
$$

Since $w_{0}=v y^{\mathrm{L}}+(1-v) y_{0}$, this gives

$$
\begin{aligned}
\Gamma W & =v(\Gamma+\Phi)(\Gamma+v \Phi)^{-1} y^{\mathrm{L}}+\Gamma(\Gamma+v \Phi)^{-1}\left(w_{0}-v y^{\mathrm{L}}\right) \\
& =\left((\Gamma+\Phi)(\Gamma+v \Phi)^{-1}-\Gamma(\Gamma+v \Phi)^{-1}\right) v y^{\mathrm{L}}+\Gamma(\Gamma+v \Phi)^{-1}\left(w_{0}-v y^{\mathrm{L}}\right) \\
& =\Phi(\Gamma+v \Phi)^{-1} v y^{\mathrm{L}}+\Gamma(\Gamma+v \Phi)^{-1} w_{0} .
\end{aligned}
$$

Thus

$$
\Gamma W=\Omega y^{\mathrm{L}}+(I-\Omega) w_{0},
$$

where the weighting matrix $\Omega$ is defined by

$$
\Omega^{-1}=I+\frac{1}{v} \Gamma \Phi^{-1}
$$

In the one-dimensional case, this reduces to $\Omega^{-1}=1+(R / \nu \phi)$, as in Lemma 2, while $\Gamma W=R W$ when $\lambda_{1}=\lambda_{2}=0$, so that this represents the flow value of wages. 
There are of course many ways to specify a wage flow that adds up to the required present value of wages. The simplest way is make the wage constant for the duration of the job, in which case the flow wage is $w_{s}=R W_{s}$. Alternatively, the wage might be state-dependent, meaning that when the aggregate state changes, the wage changes to match the wage paid to new hires. Then the flow wage is $w=\Gamma W$, so it is a weighted average of $y^{\mathrm{L}}$ and $y_{0}$, as was just shown. This has the rather implausible implication that the wage in continuing matches falls when there is a transition to the bad aggregate state. The simplest way to avoid this is to specify a wage that is constant for the life of the match if the match begins in the good aggregate state, with a lower wage initially for matches that begin in the bad state, followed by a wage increase when there is a transition to the good state. In this case the flow wages are given by

$$
\begin{aligned}
& w_{2}=R W_{2} \\
& w_{1}=w_{2}-\left(R+\lambda_{1}\right)\left(W_{2}-W_{1}\right) .
\end{aligned}
$$

The quantitative implications of these results are illustrated below (in Table 2).

\section{UNEMPLOYMENT VOLATILITY}

The volatility of unemployment can be analysed by comparing the long-run levels of unemployment associated with each aggregate state (rather than measuring standard deviations in simulated data). Although this ignores transitions associated with a change in the aggregate state, these transitions occur very rapidly, since the job-finding rate in the data is about $50 \%$ per month.

Standard parameter values are used as far as possible, following Shimer (2005) and Hall (2005). The interest rate is set at 5\% per annum, and the job destruction rate $\delta$ is set at 0.35 per annum, so that the monthly rate is about $3 \%$. The flow value of non-employment is set initially at $40 \%$ of the flow value of employment. The matching function is Cobb-Douglas. The exit rate from unemployment is about $50 \%$ per month in the data, so $\mu_{0}$ is chosen to solve the equilibrium equations with $\phi_{1} \lambda_{2}+\phi_{2} \lambda_{1}=6\left(\lambda_{1}+\lambda_{2}\right)$, meaning that the average job-finding rate is 6 per annum, the average being taken with respect to the invariant distribution of the Markov process. The expected cost of filling a vacancy in state $s$ is given by $c d_{s}=\frac{1}{\mu_{0}} \phi_{s}^{\alpha /(1-\alpha)}$.

In the NBER postwar data, the average duration of a recession is about a year, and the average duration of an expansion is about 5 years. This implies that the exit hazards are $\lambda_{2}=1 / 5$ and $\lambda_{1}=1$. Shimer (2005) reports summary statistics for detrended labour productivity (output per person), using an HP filter with smoothing parameter 100,000: the standard deviation is $0.02 \log$ points. Since the model in this paper assumes that productivity is a two-state process, it is perhaps better to measure volatility as the difference between the average levels of productivity during recessions and expansions. Using the same detrended productivity series, this difference is $0.028 \log$ points. Letting $Y_{1}$ and $Y_{2}$ denote aggregate state-contingent productivity levels, this implies that $Y_{2}$ should be about $3 \%$ above $Y_{1}$, so $Y_{2}$ is set to 1.03 , with $Y_{1}$ normalized at one. ${ }^{7}$

The variation in the informational rent is chosen so as to match the fluctuations in productivity. A simple way to do this is to set $\left(\tau_{2}-\tau_{1}\right) \Delta y=0.03$, with $y_{1}^{\mathrm{L}}=y_{2}^{\mathrm{L}}$, so that the common component of the surplus does not depend on the aggregate state, but the probability

7. Productivity could alternatively be measured as output per hour, and smaller smoothing parameters could also be justified. Since output per hour varies less than output per person, and smaller smoothing parameters (like the conventional choice of 1600) attribute more of the variance to the trend component, these alternatives would give smaller volatility estimates. The point is that by any reasonable measure, labour productivity is not very volatile. 
TABLE 1

Parameter values

\begin{tabular}{lccl}
\hline Parameter & Notation & Value & Comments \\
\hline Matching function & $m(\theta)$ & $\mu \theta^{1-\alpha}$ & See text \\
Recession exit hazard & $\lambda_{1}$ & 1 & Recession duration (1 year) \\
Expansion exit hazard & $\lambda_{2}$ & $\frac{1}{5}$ & Expansion duration (5 years) \\
& & 0.4 & Base value (Shimer) \\
Unmatched flow payoff & $y_{0}$ & 0.71 & Alternative value (Hall and Milgrom) \\
& & 1 & Extreme value (Hagedorn and Manovskii) \\
Low output & $y_{1}^{\mathrm{L}}=y_{2}^{\mathrm{L}}$ & 0.055 & Volatility of labour productivity $\left(\tau_{1}=0\right)$ \\
Informational rent & $\tau_{2} \Delta y$ & 0.35 & Shimer \\
Separation rate & $\delta$ & 0.05 & \\
Interest rate & $r$ & & \\
\hline
\end{tabular}

of drawing the high idiosyncratic component is higher in the good state. For example, if there is no informational rent in the bad state $\left(\tau_{1}=0\right)$, the rent in the good state is enough to account for the observed variation in aggregate productivity levels.

The parameter values are summarized in Table 1 .

The long-run unemployment levels are determined in the usual way as

$$
u_{s}^{*}=\frac{1}{1+\left(m\left(\theta_{s}\right)\right) / \delta} .
$$

Here $u_{s}^{*}$ is not the steady state for an economy that is permanently in state $s$, but rather the rate that would be approached if the economy continued in state $s$ for a long time, despite the transition rate $\lambda_{s}$.

In the case of a (Cobb-Douglas) matching function that is symmetric in unemployment and vacancies $(\alpha=1 / 2)$, the equilibrium values of $\phi_{1}$ and $\phi_{2}$ for the parameters in Table 1 can be obtained from the following equations:

$$
\begin{aligned}
9 \mu_{0} & =20 \phi_{1}^{2}+56 \phi_{1}-40 \phi_{2}, \\
138 \mu_{0} & =200 \phi_{2}^{2}+240 \phi_{2}-80 \phi_{1}-15 \mu_{0} \phi_{2} .
\end{aligned}
$$

When $\mu_{0}$ is chosen so as to give an average job-finding rate of 6 , the solution is $\left(\phi_{1}=4.295536223, \phi_{2}=6.340892756, \mu_{0}=39.54966078\right)$. In this example, $\rho$ and $\bar{\rho}$ are given by

$$
\begin{aligned}
& \bar{\rho}_{1}=\rho_{1}=0 \\
& \rho_{2}=\frac{3}{40 c} \\
& \bar{\rho}_{2}=\left(1+\frac{1}{2\left(1-\tau_{2}\right)}\right) \rho_{2} .
\end{aligned}
$$

In the bad state there is no informational rent, so the no-screening condition is irrelevant. In the good state the condition holds if $d_{2}=\left(\phi_{2} / \mu^{2}\right) \geq \bar{\rho}_{2}$. The equilibrium depends on $\tau_{s}$ only through $\rho_{s}$ (provided that the no-screening condition holds), and with $\tau_{1}=0, \rho_{2}$ depends on $\tau_{2}$ only through the product $\tau_{2} \Delta y$, which is set to 0.03 . The no-screening condition then holds provided that $\tau_{2} \leq 0.5605$.

Table 2 shows that informational rents can generate realistic variations in the unemployment rate. Even though the informational rent is only $3 \%$ of the productivity level, it moves the 
TABLE 2

Unemployment and wage volatility

\begin{tabular}{|c|c|c|c|c|c|}
\hline & & \multicolumn{2}{|c|}{ Baseline model } & \multicolumn{2}{|c|}{ Informational rent model } \\
\hline \multirow[t]{3}{*}{ Productivity variation } & $y_{2}^{\mathrm{L}}$ & \multicolumn{2}{|c|}{1.03} & \multicolumn{2}{|c|}{1.0} \\
\hline & $\tau_{2} \Delta y$ & \multicolumn{2}{|c|}{0} & \multicolumn{2}{|c|}{0.03} \\
\hline & $v=\alpha$ & 0.50 & 0.72 & 0.50 & 0.72 \\
\hline \multirow[t]{2}{*}{ Unemployment rates (long run) } & $u_{1}^{*}$ & $5.61 \%$ & $5.56 \%$ & $7.53 \%$ & $7.32 \%$ \\
\hline & $u_{2}^{*}$ & $5.49 \%$ & $5.50 \%$ & $5.23 \%$ & $5.25 \%$ \\
\hline \multirow[t]{3}{*}{ Wages: flat rates ${ }^{\dagger}$} & $w_{1}$ & 0.983 & 1.004 & 0.957 & 0.982 \\
\hline & $w_{2}$ & 0.989 & 1.011 & 0.966 & 0.986 \\
\hline & $\Delta w \%$ & $0.7 \%$ & $0.7 \%$ & $1.0 \%$ & $0.4 \%$ \\
\hline \multirow[t]{3}{*}{ Wages: non-decreasing rates } & $w_{1}$ & 0.966 & 0.987 & 0.933 & 0.973 \\
\hline & $w_{2}$ & 0.989 & 1.011 & 0.966 & 0.986 \\
\hline & $\Delta w \%$ & $2.4 \%$ & $2.5 \%$ & $3.5 \%$ & $1.4 \%$ \\
\hline
\end{tabular}
"The "flat rate" wage is given by $w_{s}=R W_{s}$, where $W_{s}$ is the present value of wages.
*The "non-decreasing rate" is given by $w_{1}=R W_{1}-\lambda_{1}\left(W_{2}-W_{1}\right)$, as explained in
Section 5 .

unemployment rate by about $40 \%$. To put this in context, the table also shows the unemployment rates for a baseline parameter set that matches the variance of aggregate productivity by letting the match surplus depend on the aggregate state, with no idiosyncratic variation. These baseline parameter values are as in Table 1 , but with $y_{1}^{\mathrm{L}}=p_{1}+y^{\mathrm{L}}=1, y_{2}^{\mathrm{L}}=p_{2}+y^{\mathrm{L}}=1.03$, and $y^{\mathrm{L}}=y^{\mathrm{H}}=0$. In this case, the unemployment rate is virtually constant. The table includes results for a symmetric Cobb-Douglas matching function, with $v=1 / 2$, and also for the labour share and matching elasticity parameters used by Shimer $(\alpha=v=0.72)$. Although these parameters affect the level of unemployment, they have little effect on volatility.

Table 2 also shows that even though wages are sticky with respect to cyclical changes in the distribution of the idiosyncratic component of productivity, there is nevertheless substantial cyclical wage variation. Thus although ad hoc sticky wage models have been strongly criticized by Pissarides (forthcoming) on the grounds that they generate too little wage volatility, this criticism does not apply to the informational rents model. The present value of wages is about $1 \%$ higher in the good aggregate state, and if the wage contract delivers this present value by specifying a single constant wage for all matches when the aggregate state is good, and a temporary initial wage for matches made in the bad state, then the wage rate (in new matches) is about $3.5 \%$ higher in the good state.

The parameter values given in Table 1 are of course arbitrary to some extent. For example, Hall and Milgrom (2008) have argued that the parameter $y_{0}$ should be set to 0.71 (rather then 0.4 ) in order to capture the full value of time while unemployed. Moreover, although the unemployment entry and exit rates used in Table 1 are fairly standard, a case can be made that they are either too high, or too low. The average job-finding rate, computed according to the method used by Shimer (2007), as modified by Elsby et al. (2009), was 7.3 per annum over the period January 1948 to January 2009. The average exit rate from unemployment was 0.42 by this method. On the other hand the job-finding rate computed from gross flows data by Fujita and Ramey (2009) was 5.0 per annum over the period January 1976 to December 2005, and the unemployment exit rate was 0.24 . To a large extent the differences in these rates reflect different choices in the way a two-state model of the labour market is used to interpret data in which there are large flows into and out of the labour force, as well as large flows directly from one job to another. But whatever the source of the differences it is clearly 
TABLE 3

Unemployment volatility (alternative parameter values)

\begin{tabular}{lccccccc}
\hline & & Baseline rates & High $\phi$ & Low $\phi$ & High $\delta$ & Low $\delta$ & High $y_{0}$ \\
\hline \multirow{4}{*}{ Variant } & $y_{0}$ & 0.4 & 0.4 & 0.4 & 0.4 & 0.4 & 0.7 \\
\multirow{2}{*}{ Long run } & $\phi$ & 6 & 7.5 & 5 & 6 & 6 & 6 \\
Unemployment rates & $\delta$ & 0.35 & 0.35 & 0.35 & 0.45 & 0.2 & 0.35 \\
& $u_{1}^{*}$ & $7.53 \%$ & $6.38 \%$ & $8.65 \%$ & $9.10 \%$ & $4.99 \%$ & $9.26 \%$ \\
& $u_{2}^{*}$ & $5.23 \%$ & $4.21 \%$ & $6.24 \%$ & $6.67 \%$ & $3.01 \%$ & $5.10 \%$ \\
\hline
\end{tabular}

important to check whether the unemployment volatility shown in Table 2 is robust over a range of plausible parameter values. Table 3 shows that the results are indeed robust in this respect. The equilibrium level of unemployment is of course sensitive to changes in the entry and exit rates, but the difference between the unemployment rates in the good and bad states is not at all sensitive to these changes. Similarly, when $y_{0}$ is set to 0.7 , as recommended by Hall and Milgrom (2008), the volatility of unemployment persists; in fact this setting gives considerably more volatility than the value used by Shimer (2005).

Hagedorn and Manovskii (2008) have argued that the Mortensen-Pissarides model can generate realistic unemployment fluctuations if the value of the worker's outside option is close to the value of production. In the model considered here, this means setting $y_{0}$ near 1 . Hagedorn and Manovskii calibrated $y_{0}$ as 0.955 , with $v=0.052$. Table 4 explores the implications of these parameter values, in the model with no informational rents.

When the workers' outside opportunities are almost as good as their market opportunities, unemployment is indeed more volatile. Mortensen and Nagypál (2007) argue that this is quite unrealistic, since it implies that the average worker has little to gain from employment. Moreover, as Costain and Reiter (2008) and Hornstein et al. (2005) point out, it also implies implausibly large changes in unemployment rates in response to changes in unemployment benefits. Table 4 illustrates yet another difficulty: even the rather extreme value of $y_{0}$ advocated by Hagedorn and Manovskii (2008) generates only about a 20\% difference between the unemployment rates in the two states. The last column of the table shows that volatility increases sharply as $y_{0}$ approaches 1 . It might seem that everyone should be unemployed in the bad state if $y_{0}=1$, since this means that jobs produce no surplus, and in order to move workers into jobs, it is necessary to expend resources on vacancy costs. But the bad state is not expected to last very long, and jobs generate a (small) surplus in the good state. Moving some workers into jobs in the bad state reduces congestion in the matching process when the economy switches to the good state. For an employer, it is worthwhile to create vacancies in the bad state in anticipation of a transition to the good state, because when that transition occurs the aggregate component of productivity will increase. If a transition is unlikely, the unemployment rate in the bad state will be high. But in the data, recessions are relatively shortlived, so the Hagedorn and Manovskii calibration yields a relatively small difference between the unemployment rates in the good and bad states.

Table 5 shows that in a comparison of steady states with no transitions, the Hagedorn and Manovskii calibration gives much more volatility. ${ }^{8}$ But this is largely beside the point, since

8. Here $\mu_{0}$ cannot be chosen so as to equate the average job-finding rate in the model with the empirical value, because each realization of the aggregate state is permanent, so there is no invariant distribution that can be used to take an average. Instead, $\mu_{0}$ is chosen to solve the equilibrium equations with $\phi_{1}+\phi_{2}\left(\lambda_{1} / \lambda_{2}\right)=6\left(1+\left(\lambda_{1} / \lambda_{2}\right)\right)$, where $\lambda_{1} / \lambda_{2}=5$, as in the baseline model. This corresponds to taking a limit as the transition rates become small, while their ratio stays fixed. 
REVIEW OF ECONOMIC STUDIES

TABLE 4

Unemployment volatility (no informational rent)

\begin{tabular}{lcccccc}
\hline & & Baseline rates & High $y_{0}$ & Low $v$ & High $y_{0}$, low $v$ & Higher $y_{0}$, low v \\
\hline Variant & $y_{0}$ & 0.4 & 0.955 & 0.4 & 0.955 & 1 \\
Long run & $v$ & 0.5 & 0.5 & 0.052 & 0.052 & 0.052 \\
Unemployment rates & $u_{1}^{*}$ & $5.61 \%$ & $6.56 \%$ & $5.58 \%$ & $6.19 \%$ & $8.08 \%$ \\
& $u_{2}^{*}$ & $5.49 \%$ & $5.34 \%$ & $5.50 \%$ & $5.39 \%$ & $5.18 \%$ \\
\hline
\end{tabular}

TABLE 5

Unemployment volatility with no transitions $\left(\lambda_{1}=\lambda_{2}=0\right)$

\begin{tabular}{lcccccc}
\hline & & Baseline rates & High $y_{0}$ & Low $v$ & High $y_{0}$, low $v$ & Informational rent \\
\hline Variant & $y_{0}$ & 0.4 & 0.955 & 0.4 & 0.955 & 0.4 \\
\multirow{2}{*}{ Long run } & $v$ & 0.5 & 0.5 & 0.052 & 0.052 & 0.5 \\
Unemployment rates & $u_{1}^{*}$ & $5.63 \%$ & $6.85 \%$ & $5.66 \%$ & $7.37 \%$ & $7.24 \%$ \\
& $u_{2}^{*}$ & $5.49 \%$ & $5.30 \%$ & $5.48 \%$ & $5.25 \%$ & $5.26 \%$ \\
\hline
\end{tabular}

the volatility in the data is generated by a single economy with transitions between states, while Table 5 compares the steady states of two different economies. This is illustrated by considering the effects of the very low value for the labour share parameter used by Hagedorn and Manovskii. Although this generates additional volatility in the comparison of two unrelated economies shown in Table 5, it actually reduces volatility in the more relevant comparison of steady states of a single stochastic economy, as shown in Table 4. Again, the reason for this is evidently that when the employer gets most of the surplus there is a stronger tendency to create vacancies in the bad state in anticipation of a transition to the good state, and this effect is absent in the model without transitions.

\subsection{Unemployment volatility and efficiency}

It is difficult to believe that the increase in unemployment seen in recessions is an efficient response to a fall in productivity, and Shimer (2005) showed that when the MortensenPissarides model is calibrated so as to satisfy the Hosios (1990) efficiency condition, it indeed generates very little unemployment volatility. The Hosios condition felicitously balances two sources of inefficiency. On the one hand, the incentive for employers to create vacancies is diluted because although the employer pays the vacancy cost, the worker claims some of the surplus from the resulting match; this tends to reduce the number of vacancies below the efficient level. But the employer fills the vacancy at the expense of other employers, and pays no price for this, so that there is an opposing tendency to increase vacancies above the efficient level. The introduction of private information does not affect the efficient level of unemployment (given that bargaining outcomes are privately efficient), but it does disturb the Hosios balance.

The relationship between informational rents, volatility and efficiency is illustrated in Table 6. The labour share parameter $v$ and the matching elasticity parameter $\alpha$ are either 0.5 or 0.72 , as in Table 2. The Hosios condition means that these two parameters are equal, and the unemployment rates in the first three columns of the table are therefore efficient (with no private information). The first two columns, and the first two columns with informational rents, are as in Table 2, using a Cobb-Douglas matching function $m(\theta)=\mu \theta^{1-\alpha}$, with $\mu_{0}$ set to match the average job-finding rate $(\phi=6)$. 
TABLE 6

Unemployment volatility and efficiency

\begin{tabular}{lcccccccc}
\hline & & \multicolumn{3}{c}{ No informational rent } & \multicolumn{3}{c}{ Informational rent } \\
\hline Productivity variation & $y_{2}^{\mathrm{L}}$ & \multicolumn{4}{c}{1.03} & \multicolumn{3}{c}{1.0} \\
& $\tau_{2} \Delta y$ & \multicolumn{3}{c}{0} & \multicolumn{3}{c}{0.03} \\
Matching elasticity & $\alpha$ & 0.50 & 0.72 & 0.50 & 0.50 & 0.50 & 0.72 & 0.50 \\
Labour weight & $v$ & 0.50 & 0.72 & 0.50 & 0.72 & 0.50 & 0.72 & 0.72 \\
Match efficiency & $\mu_{0}$ & 65.3 & 2703.3 & 60.3 & 60.3 & 39.6 & 1044.6 & 60.3 \\
Unemployment & $u_{1}^{*}$ & $5.61 \%$ & $5.56 \%$ & $5.83 \%$ & $9.10 \%$ & $7.53 \%$ & $7.32 \%$ & $9.72 \%$ \\
Rates & $u_{2}^{*}$ & $5.49 \%$ & $5.50 \%$ & $5.72 \%$ & $8.92 \%$ & $5.23 \%$ & $5.25 \%$ & $5.07 \%$ \\
\hline
\end{tabular}

TABLE 7

Unemployment volatility and bargaining weights

\begin{tabular}{lcccccccc}
\hline & $v$ & $\frac{3}{4}$ & $\frac{1}{2}$ & $\frac{1}{3}$ & $\frac{1}{4}$ & $\frac{1}{5}$ & $\frac{1}{10}$ & 0 \\
\hline Unemployment & $u_{1}^{*}$ & $10.24 \%$ & $7.53 \%$ & $6.71 \%$ & $6.41 \%$ & $6.25 \%$ & $5.98 \%$ & $5.73 \%$ \\
Rates & $u_{2}^{*}$ & $5.05 \%$ & $5.23 \%$ & $5.32 \%$ & $5.36 \%$ & $5.38 \%$ & $5.43 \%$ & $5.47 \%$ \\
\hline
\end{tabular}

The main result in Table 6 is shown in the last column. Here $\mu_{0}$ is set to give $\phi=6$ on average when $\alpha=0.5$ and $v=0.72$. The efficient unemployment rates for this matching function are shown in the third column: the unemployment rate is around $5.75 \%$ in both states, with a negligible difference between the states. The implications of the Hosios condition are illustrated in the fourth column: because $v>\alpha$, the unemployment rate is well above the (complete information) efficient level, but the difference between the two states is still negligible. The last column describes a situation in which the Hosios inefficiency is offset by informational rents in the good state (and in fact the unemployment rate is slightly below the efficient level), but this balance breaks down in recessions, leading to a lot of inefficient unemployment.

\subsection{The weighted NBS}

The NBS gives equal weight to the employer and the worker, in the sense that each has an equal chance of being allowed to choose an incentive-compatible mechanism to divide the surplus. The motivation for this is Nash's symmetry axiom: if the bargaining problem is symmetric, there is no reason to expect an asymmetric outcome. The weighted version of the NBS can be used to explore the implications of allowing unequal bargaining weights, and in particular to illustrate the connection between informational rents and bargaining weights. Starting from the result given in Table 2, Table 7 shows the effect of varying the probability $v$ that the worker chooses the mechanism, while keeping $\alpha=1 / 2$ and all of the other parameters at the values used in Table 2 (and again allowing $\mu_{0}$ to vary so as to maintain the average job-finding rate). The main point here is that the informational rents that drive unemployment fluctuations disappear as the worker's bargaining weight drops to zero. On the other hand, there is substantial volatility for intermediate values of $v$ below $1 / 2$, and volatility increases sharply for $v>1 / 2$. 


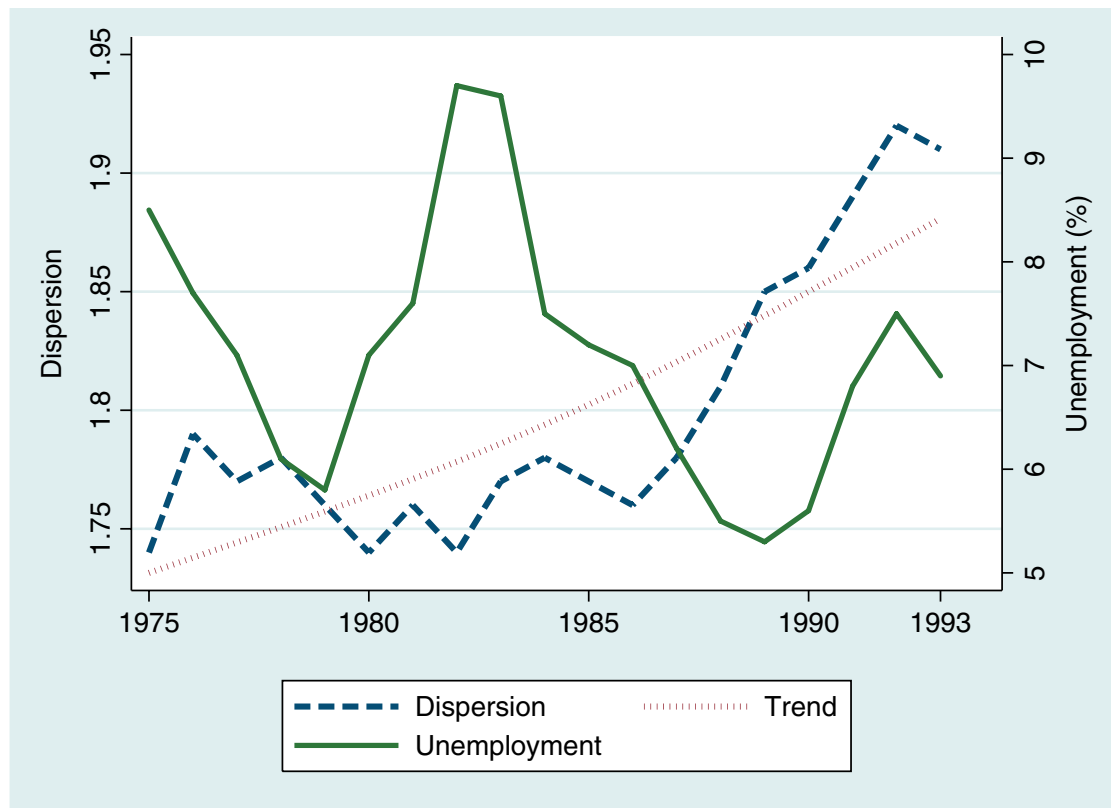

FIGURE 3

Cyclical variation in productivity dispersion

\subsection{Cyclical movements in the dispersion of productivity}

It has been shown that small variations in informational rents generate large variations in the unemployment rate. It is of course difficult to obtain evidence of such variations, precisely because they are due to private information. But it seems reasonable that procyclical variations in informational rents would be associated with procyclical variations in the variability of labour productivity across employers. Figure 3 shows some evidence in favour of such variations. Dunne et al. (2004) analysed productivity dispersion across manufacturing plants over the period 1975-1992. As Dunne et al. point out, dispersion increased over this period, especially from 1986 to 1992. Figure 3 shows the Dunne et al. productivity dispersion series, overlaid on a Hodrick-Prescott estimate of the trend, in relation to the US unemployment rate. ${ }^{9}$ Productivity dispersion is weakly procyclical over this (admittedly short) period (the correlation between unemployment and detrended productivity dispersion is -0.14 ).

\section{ARE INFORMATIONAL RENTS BIGGER WHEN MORE INFORMATION IS PRIVATE?}

A key feature of the model is that the dispersion of the privately observed component of the match surplus increases in the good aggregate state, and this increased dispersion gives rise to an increase in informational rent. An important theoretical issue is then whether the increase in informational rent arises merely from the assumption that the privately observed portion of the

9. The figure includes data for the period 1975-1993: later data on productivity dispersion are not available. The measure of dispersion is the difference between $\log$ productivity at the 90th and the 10th percentiles of the distribution of output per worker, where the distribution refers to the productivity of an hour worked, so larger plants have more weight. I thank Lucia Foster for these data. 
surplus takes just two possible values, with the worker optimally choosing to demand one of these values or the other. Given just two possible realizations, a small increase in the probability of the high surplus is not enough to induce the worker to switch the optimal demand from the low value to the high value, but in the case of a more general distribution an improvement in the distribution would induce the worker to make a more aggressive demand, and it is not clear that this would leave a larger informational rent for the employer.

One way to analyse this is to consider an alternative situation in which the surplus is distributed continuously over an interval. Without loss of generality, the lowest possible surplus can be taken to be 0 . Thus consider a worker making a take-it-or-leave-it demand to an employer in a match where the surplus is $a+s$, with $a>0$ and $s$ distributed over the interval $[0, b]$. Let $y=s / b$, distributed on $[0,1]$ according to the distribution function F. The worker's payoff from a demand $a+b x$ is zero if this demand exceeds the actual surplus, which is the case if $x>y$. Thus the worker's expected payoff is $(a+b x) /(1-F(x))$.

A simple way to formulate the question is to ask whether an increase in $b$ leads to an increase in the informational rent. An increase in $b$, with $F$ fixed, magnifies the surplus in every state of the world. This is known to the worker, and it is assumed that the employer's only options are to say yes or no to a single offer made by the worker. The question is whether the employer's expected payoff increases when the distribution improves in this way, even though the change in the distribution is common knowledge, and the worker has all of the bargaining power. In the absence of private information, the employer would get no surplus in this situation. So any positive payoff for the employer arises solely from the employer's informational advantage, and is thus an informational rent.

The informational rent when the worker demands $x$ is $R=b[E \max (y, x)-x]$, which can be written as

$$
R=b \int_{x}^{1}[1-F(t)] d t .
$$

The worker's problem can be stated as

$$
\max _{x \in[0,1]}(c+x)(1-F(x)),
$$

where $c=a / b$. First, it is clear that an increase in $b$ implies an increase in the worker's optimal demand. Indeed suppose that $b$ increases from $b_{0}$ to $b_{1}$, meaning that $c$ decreases from $c_{0}$ to $c_{1}$ (with $a$ fixed), and let the corresponding optimal choices of $x$ be $x_{0}$ and $x_{1}$. Then optimality implies

$$
\begin{aligned}
& \left(c_{0}+x_{0}\right)\left(1-F\left(x_{0}\right)\right) \geq\left(c_{0}+x_{1}\right)\left(1-F\left(x_{1}\right)\right) \\
& \left(c_{1}+x_{1}\right)\left(1-F\left(x_{1}\right)\right) \geq\left(c_{1}+x_{0}\right)\left(1-F\left(x_{0}\right)\right) .
\end{aligned}
$$

Since the expected payoff is positive for $x=0$, and zero for $F(x)=1$, it follows that $1-F(x)$ is positive at the optimum. Thus, the above revealed preference inequalities can be written as

$$
\frac{c_{0}+x_{0}}{c_{0}+x_{1}} \geq \frac{1-F\left(x_{1}\right)}{1-F\left(x_{0}\right)} \geq \frac{c_{1}+x_{0}}{c_{1}+x_{1}}
$$

which implies $\Delta x \Delta c \leq 0$. Thus, an increase in $b$ implies an increase in $x$.

Next, the pooling solution $(x=0)$ is optimal if the opportunity cost of screening is high relative to the expected gains. Indeed, pooling is optimal if and only if $(c+x)(1-F(x)) \leq c$ for all $x \in[0,1]$, that is, if

$$
\max _{x \in[0,1]} x\left(\frac{1}{F(x)}-1\right) \leq c
$$


For example, if $F$ is the uniform distribution, pooling is optimal if $c \leq 1$. On the other hand, if $F$ is differentiable at 0 , then $F(x) \approx x F^{\prime}(0)$, for $x$ near 0 . Thus, if $F$ has zero density at the origin, then pooling cannot be optimal for any value of $c$.

Obviously, if pooling is optimal, and remains so after an increase in $b$, then the informational rent increases with $b$, just as in the case of the two-point distribution analysed above. The issue considered here is whether this result is limited to the case where pooling is optimal. In fact, it is not: it is shown in Appendix B that it holds for a reasonably broad class of distributions.

If pooling is not optimal, and if $F$ has a density $f$, the optimal choice of $x$ must satisfy the first-order condition

$$
(1-F(x))-f(x)(c+x)=0 .
$$

This can be written as

$$
\frac{1}{h(x)}=\frac{a}{b}+x,
$$

where $h$ is the hazard function.

The simplest example is the uniform distribution. In that case if $b<a$, pooling is optimal, so a (small) increase in $b$ necessarily gives an increase in the informational rent. For some distributions, when $b$ increases to the point where screening becomes optimal, there is then a downward jump in the rent. The two-point distribution has this property: when the probability of the good state or the size of the surplus in the good state rise beyond a certain point, the informational rent disappears. But it will be shown that in the case of a uniform distribution there is no downward jump, and that further increases in $b$ lead to increases in $R$, even though the worker screens more aggressively.

For a uniform distribution with $b>a$, the optimal screening price is

$$
x=\frac{1}{2}\left(1-\frac{a}{b}\right) .
$$

The rent is given by

$$
\begin{aligned}
R & =b \int_{x}^{1}(1-t) d t=b\left(\frac{1}{2}-x+\frac{1}{2} x^{2}\right) \\
& =\frac{a}{8}\left(2+\frac{b}{a}+\frac{a}{b}\right)
\end{aligned}
$$

which is increasing in $b$ (when $b>a$ ). Thus, when the surplus is magnified, the informational rent increases, regardless of whether pooling or screening is optimal. ${ }^{10}$

\section{ALTERNATIVE EXPLANATIONS OF UNEMPLOYMENT VOLATILITY}

Starting with Shimer (2005) and Costain and Reiter (2008), the literature on unemployment volatility has developed very rapidly. The main developments have recently been reviewed by

10. More general versions of this result for a class of beta distributions are given in Appendix B. Thus the result for the case of a two-point distribution of the private information variable is reasonably robust. But it should be noted that the result certainly does not hold for all distributions, or even for all beta distributions. For example, if $F(y)=y^{3 / 4}$, with $a=1$, screening becomes optimal when $b=2.1165$. There is a downward jump in the informational rent at this point, and after this the rent continues to fall until $b=2.2684$; beyond this point the rent is increasing in $b$. 
Mortensen and Nagypál (2007), and by Pissarides (forthcoming). The focus has been largely on modifications of the wage-setting mechanism that increase the elasticity of the job-finding rate with respect to productivity. The main point is that if the profit margin associated with a filled job is very small, then small changes in productivity can have large effects on profits, and therefore on vacancy creation.

As a point of reference, consider a simple wage-setting mechanism in which the wage is set one day at a time. Each day, either the worker or the employer is selected to make a take-it-or-leave-it offer setting the wage for that day. Wages and profits are then given by

$$
\begin{aligned}
& w_{0}=v y+(1-v) y_{0} \\
& \pi_{0}=y-w_{0}=(1-v)\left(y-y_{0}\right),
\end{aligned}
$$

where $v$ is the probability that the worker makes the offer. Thus, $w_{0}$ is a weighted average of the worker's productivity inside and outside of the match. It was shown in Lemma 2 above that the Nash bargaining mechanism used in the Mortensen-Pissarides model yields a wage that is an average of $y$ and $w_{0}$, with weights that depend on the job-finding rate. Thus the wage is a nested weighted average of $y$ and $y_{0}$, and since $\Phi$ is close to 1 for standard parameter values, the Nash wage is heavily influenced by the worker's job-finding prospects. The worker gets a bigger share of the surplus when the job-finding rate increases, but even in a recession the worker gets a very large share.

The elasticity of the job-finding rate with respect to productivity is governed by the free entry condition. Not much is lost by assuming that the matching function is Cobb-Douglas, and that it is symmetric in the number of vacancies and the number of unemployed workers, so that $\phi=\mu \sqrt{\theta}$. In this case the free entry condition can be written as

$$
\frac{c}{\mu^{2}} \phi=\frac{y-w}{r+\delta}
$$

Thus, the volatility of the job-finding rate is the same as the volatility of the profit flow (with $\delta$ fixed). Using Lemma 2, the elasticity of $\phi$ is given by

$$
\frac{\partial \log (\phi)}{\partial \log (y)}=\frac{y}{y-y_{0}} \frac{1}{1+\Phi} .
$$

This elasticity is not large unless an unmatched worker is almost as productive as a matched worker, as in Hagedorn and Manovskii (2008).

If the wage is fixed, then

$$
\frac{d \log (\phi)}{d \log (y)}=\frac{y}{y-w} .
$$

Thus, as Hall (2005) pointed out, if the wage is sticky the response of the job finding rate to productivity may be very elastic, but this is true only if the wage is set at a level that is close to the productivity level.

If the wage is negotiated day by day, then $y-w=(1-v)\left(y-y_{0}\right)$, so

$$
\frac{d \log (\phi)}{d \log (y)}=\frac{y}{y-y_{0}} .
$$

This is closely related to the point made by Hall and Milgrom (2008); if the worker's option to find another match is regarded as being irrelevant, then there is no link between $\phi$ and $w$, so the elasticity of the job finding rate is increased. But again (when the wage is negotiated 
day by day), the elasticity is not large unless the value of the worker's outside option is almost as good as the value of working. ${ }^{11}$

Nagypál (2005) and Mortensen and Nagypál (2007) develop an extended version of the Mortensen-Pissarides model that is capable of matching both the volatility of unemployment and the observed negative correlation of unemployment and vacancies. They introduce four modifications of the basic model. First, exogenous job destruction shocks provide an additional source of unemployment movements (without being so large as to overturn the negative $\mathrm{U}-\mathrm{V}$ correlation generated by productivity shocks). Second, there are substantial job-to-job flows. Although the job separation rate is relatively constant, as was argued by Hall (2006), the flow from employment to unemployment increases in recessions, as was shown by Elsby et al. (2009), because the job-to-job flow decreases. Third, in order to post a vacancy, the employer must pay a lump sum hiring cost (in addition to the flow cost of maintaining the vacancy). Fourth, the wage bargaining is day-to-day (as described above), so the wage is not affected by the job-finding rate. Taken together, these four modifications lead to a model that can match the data if the lump sum hiring cost is sufficiently large (about nine months' worth of profits). But the extended model is unwieldy, and the empirical plausibility of the required hiring costs is questionable. Moreover, as Pissarides (forthcoming) points out, if the observed fluctuations in the job destruction rate are interpreted in the context of the original MortensenPissarides model (rather than being treated as exogenous changes in the rate at which matches are destroyed), they do not generate much volatility in unemployment, because they are not associated with changes in the job creation rate. The informational rents model developed here introduces just one modification of the standard model, and thereby explains the same facts in a more parsimonious way.

\section{CONCLUSION}

Rent is a powerful economic force, and private information is a pervasive rent source, so it is plausible that private information can help to explain features of the economy that are otherwise difficult to understand. It has been shown here that the introduction of private information in an otherwise standard model of unemployment fluctuations provides a reasonable explanation for the volatility of unemployment. In the standard Mortensen-Pissarides model, unemployment fluctuations are driven by labour productivity shocks. In the data, these shocks are small, and the implied fluctuations in unemployment are also small, and much smaller than the fluctuations in the data. But if the productivity realizations are privately observed by employers, the implications for unemployment fluctuations are quite different. Small productivity shocks generate informational rents for employers, and small rents are a powerful job creation force. Thus, privately observed productivity shocks of the magnitude seen in the data can generate realistic unemployment fluctuations.

11. In the Hall-Milgrom model, the employer pays a bargaining cost $\gamma$ each day until a wage agreement is reached. The relevance of this can be illustrated in a simplified version of the model in which the match duration is known in advance, and there is no discounting. Then on a day when the worker is selected to make the offer, the wage is $y+\gamma$ (leaving the employer indifferent between saying yes or no), and when the employer makes the offer the wage is $y_{0}$. The average profit flow is $(1-v)\left(y-y_{0}-\gamma\right)$, so the elasticity of $\phi$ can be made large even though $y_{0}$ is not close to $y$, by choosing a suitable value of $\gamma$. More generally, although the Hall-Milgrom model allows for a stochastic match duration, with an enhanced separation risk while bargaining continues, the parameters $y_{0}$ and $\gamma$ affect the bargaining outcome only through their sum, if the continuation value of unemployment is held constant. In the calibrated model this sum is 0.98 (with $y_{0}=0.71$ and $\gamma=0.27$ ), while $y$ varies between 0.9731 and 1.0243 . This leaves very little room for profit, and it means that a small productivity change implies a big proportional change in profits. 


\section{APPENDIX A. THE NBS: ONE-SIDED PRIVATE INFORMATION WITH TWO TYPES}

Myerson (1984) proposed the NBS as a generalization of the Nash bargaining solution suitable for a broad class of two-person bargaining problems with private information. There is a finite set of decisions, $D$. A direct revelation mechanism $\mu$ specifies the probabilities of the various decisions, conditional on information reported by the players. The payoff for player $i, u_{i}(d, t)$, depends on the decision $d$, and on the type vector, t. Thus when types are reported truthfully, the expected payoff of player $i$ of type $t_{i}$ is

$$
U_{i}\left(\mu \mid \mathrm{t}_{i}\right)=\sum_{t \in T} \sum_{d \in D} p\left(\mathrm{t} \mid \mathrm{t}_{i}\right) \mu(d, \mathrm{t}) u_{i}(d, \mathrm{t}),
$$

where $p$ gives the probability of the type vector $\mathrm{t}$, conditional on $\mathrm{t}_{i}$, and $\mu(d, \hat{t})$ is the probability that $d$ is chosen, given that types are reported as $\hat{t}$.

Consider a two-player bargaining problem in which the surplus to be divided is either $S^{\mathrm{H}}$ or $S^{\mathrm{L}}$, with probabilities $\tau$ and $1-\tau$, where the realization of $S$ is known to player 1 , but not to player 2 . There are three decisions, $D=\left\{d_{0}, d_{1}, d_{2}\right\}$, where $d_{0}$ is the conflict outcome in which each player gets zero, $d_{1}$ means that player 1 gets $S$, the realized value of the surplus (and player 2 gets zero), and $d_{2}$ means that player 2 gets $S^{\mathrm{H}}$, and player 1 gets $S-S^{\mathrm{H}}$. Thus, the payoffs depend on whether player 1 is of type $H$ or $L$, as follows:

\begin{tabular}{|c|c|c|c|}
\hline$\left(u_{1}, u_{2}\right)$ & $d_{0}$ & $d_{1}$ & $d_{2}$ \\
\hline \hline $1 \mathrm{H}$ & $(0,0)$ & $\left(S^{\mathrm{H}}, 0\right)$ & $\left(0, S^{\mathrm{H}}\right)$ \\
\hline $1 \mathrm{~L}$ & $(0,0)$ & $\left(S^{\mathrm{L}}, 0\right)$ & $\left(S^{\mathrm{L}}-S^{\mathrm{H}}, S^{\mathrm{H}}\right)$ \\
\hline
\end{tabular}

It is not difficult to show that there are incentive-efficient mechanisms that select $d_{0}$ with positive probability if and only if $\tau \geq\left(S^{\mathrm{L}} / S^{\mathrm{H}}\right)$ (see Kennan, 1986). This condition does not hold in the model considered in this paper. Incentive compatibility then requires that the probability of choosing $d_{1}$ is the same in both states, since player 1 's payoff is increasing in this probability, regardless of the state. Let $\alpha$ be the multiplier associated with this constraint, and let $\mu_{i}$ be the probability of choosing $d_{i}$, for $i \in\{1,2\}$.

Myerson's Theorem 5 gives a set of conditions which must hold for every mechanism $\mu$ in the set of NBSs. It will be shown that there is only one mechanism that satisfies these conditions. Since the NBS set is not empty (according to Myerson's Theorem 2), this is an NBS, and it is unique.

The conditions are as follows (with Myerson's numbering in brackets). The mechanism $\mu$ is incentive-efficient, and there exist $\lambda \in \mathbb{R}^{3}, \omega \in \mathbb{R}^{3}$ and $\alpha \geq 0$, such that:

$[(8.6)] \lambda \geq 0, \omega \geq 0$ and $(\lambda, \omega) \neq 0$.

$[(8.7)] \mu$ is an optimal solution of the primal problem for $\lambda$. That is, $\mu$ maximizes the Lagrangean

$$
\ell=\lambda_{2} U_{2}(\mu)+\lambda_{1 \mathrm{~L}} U_{1 \mathrm{~L}}(\mu)+\lambda_{1 \mathrm{H}} U_{1 \mathrm{H}}(\mu)+\alpha\left(U_{1 \mathrm{H}}(\mu)-U_{1 \mathrm{H}}^{*}(\mu, L)\right),
$$

with $\alpha=0$ if $U_{1 \mathrm{H}}(\mu)>U_{1 \mathrm{H}}^{*}(\mu, L)$, where $U_{1 \mathrm{H}}^{*}(\mu, L)$ is player 1 's payoff when falsely reporting type $L$. This Lagrangean can be rewritten in terms of "virtual evaluations" $V$ as

$$
\ell=\sum_{d \in D} \mu_{\mathrm{H}}(d)\left(V_{1 \mathrm{H}}(d)+V_{2 \mathrm{H}}(d)\right)+\sum_{d \in D} \mu_{\mathrm{L}}(d)\left(V_{1 \mathrm{~L}}(d)+V_{2 \mathrm{~L}}(d)\right),
$$

where

$$
\begin{aligned}
& V_{1 \mathrm{H}}(d)=\left(\lambda_{1 \mathrm{H}}+\alpha\right) u_{1 \mathrm{H}}(d) \\
& V_{2 \mathrm{H}}(d)=\lambda_{2} \tau u_{2 \mathrm{H}}(d) \\
& V_{1 \mathrm{~L}}(d)=\lambda_{1 \mathrm{~L}} u_{1 \mathrm{~L}}(d)-\alpha u_{1 \mathrm{H}}(d) \\
& V_{2 \mathrm{~L}}(d)=\lambda_{2}(1-\tau) u_{2 \mathrm{~L}}(d) .
\end{aligned}
$$

$[(8.8)] \alpha$ is an optimal solution of the dual problem for $\lambda$. That is, $\alpha$ solves

$$
\min _{\alpha \geq 0} \sum_{t \in T}\left(\max _{d \in D} \sum_{i=1}^{2}\left(V_{i \mathrm{~L}}(d)+V_{i \mathrm{H}}(d)\right)\right) .
$$


[(8.9)] The virtual evaluations satisfy the following "warrant" equations

$$
\begin{aligned}
\lambda_{1 \mathrm{~L}} \omega_{1 \mathrm{~L}}-\alpha \omega_{1 \mathrm{H}} & =\frac{1}{2} \max _{d \in D}\left(V_{1 \mathrm{~L}}(d)+V_{2 \mathrm{~L}}(d)\right) \\
\left(\lambda_{1 \mathrm{H}}+\alpha\right) \omega_{1 \mathrm{H}} & =\frac{1}{2} \max _{d \in D}\left(V_{1 \mathrm{H}}(d)+V_{2 \mathrm{H}}(d)\right) \\
\lambda_{2} \omega_{2} & =\lambda_{1 \mathrm{~L}} \omega_{1 \mathrm{~L}}+\lambda_{1 \mathrm{H}} \omega_{1 \mathrm{H}} .
\end{aligned}
$$

[(8.10)] Each type of each agent gets at least the warranted expected utility:

$$
\begin{aligned}
\omega_{2} & \leq U_{2}(\mu)=\left(\tau \mu_{\mathrm{H}}\left(d_{2}\right)+(1-\tau) \mu_{\mathrm{L}}\left(d_{2}\right)\right) S^{\mathrm{H}} . \\
\omega_{1 \mathrm{H}} & \leq U_{1 \mathrm{H}}(\mu)=\mu_{\mathrm{H}}\left(d_{1}\right) S^{\mathrm{H}} \\
\omega_{1 \mathrm{~L}} & \leq U_{1 \mathrm{~L}}(\mu)=S^{\mathrm{L}}-\mu_{\mathrm{L}}\left(d_{2}\right) S^{\mathrm{H}} .
\end{aligned}
$$

[(8.5)] The warranted and actual expected utilities satisfy the following complementary slackness conditions:

$$
\begin{aligned}
\omega_{2} & =U_{2}(\mu) \text { or } \lambda_{2}=0 \\
\omega_{1 \mathrm{H}} & =U_{1 \mathrm{H}}(\mu) \text { or } \lambda_{1 \mathrm{H}}=0 \\
\omega_{1 \mathrm{~L}} & =U_{1 \mathrm{~L}}(\mu) \text { or } \lambda_{1 \mathrm{~L}}=0 .
\end{aligned}
$$

The first step is to maximize the Lagrangean. This is done by choosing a decision in each state that maximizes the sum of the virtual evaluations, the relevant sums being given by

$$
\begin{aligned}
& V_{1 \mathrm{H}}\left(d_{1}\right)+V_{2 \mathrm{H}}\left(d_{1}\right)=\left(\lambda_{1 \mathrm{H}}+\alpha\right) S^{\mathrm{H}} \\
& V_{1 \mathrm{H}}\left(d_{2}\right)+V_{2 \mathrm{H}}\left(d_{2}\right)=\lambda_{2} \tau S^{\mathrm{H}} \\
& V_{1 \mathrm{~L}}\left(d_{1}\right)+V_{2 \mathrm{~L}}\left(d_{1}\right)=\lambda_{1 \mathrm{~L}} S^{\mathrm{L}}-\alpha S^{\mathrm{H}} \\
& V_{1 \mathrm{~L}}\left(d_{2}\right)+V_{2 \mathrm{~L}}\left(d_{2}\right)=\lambda_{1 \mathrm{~L}} S^{\mathrm{L}}+\left(\lambda_{2}(1-\tau)-\lambda_{1 \mathrm{~L}}\right) S^{\mathrm{H}} .
\end{aligned}
$$

The dual problem is

$$
\begin{aligned}
& \min _{\alpha \geq 0}\left(\max _{d}\left(V_{1 \mathrm{H}}(d)+V_{2 \mathrm{H}}(d)\right)+\max _{d}\left(V_{1 \mathrm{~L}}(d)+V_{2 \mathrm{~L}}(d)\right)\right) \\
= & \min _{\alpha \geq 0}\left(\max \left(\lambda_{1 \mathrm{H}}+\alpha, \lambda_{2} \tau\right) S^{\mathrm{H}}+\lambda_{1 \mathrm{~L}} S^{\mathrm{L}}+\max \left(\lambda_{2}(1-\tau)-\lambda_{1 \mathrm{~L}},-\alpha\right) S^{\mathrm{H}}\right) .
\end{aligned}
$$

If $d_{2}$ is chosen with probability 1 in the low state, then $U_{1 \mathrm{~L}}$ is negative, so the mechanism is not feasible. Thus, it must be optimal to choose $d_{1}$ in the low state. It must also be optimal to choose $d_{1}$ in the high state, since otherwise $d_{2}$ has probability 1 in the high state, and then the incentive compatibility constraint implies that $d_{2}$ has probability 1 in the low state as well.

The dual problem can therefore be written as

$$
\min _{\alpha \geq 0}\left(V_{1 \mathrm{H}}\left(d_{1}\right)+V_{2 \mathrm{H}}\left(d_{1}\right)+V_{1 \mathrm{~L}}\left(d_{1}\right)+V_{2 \mathrm{~L}}\left(d_{1}\right)\right)=\lambda_{1 \mathrm{H}} S^{\mathrm{H}}+\lambda_{1 \mathrm{~L}} S^{\mathrm{L}}
$$

The optimality of $d_{1}$ also implies that the warrant equations can be written as

$$
\begin{aligned}
\lambda_{1 \mathrm{~L}}\left(\omega_{1 \mathrm{~L}}-\frac{1}{2} S^{\mathrm{L}}\right)-\alpha\left(\omega_{1 \mathrm{H}}-\frac{1}{2} S^{\mathrm{H}}\right) & =0 \\
\left(\lambda_{1 \mathrm{H}}+\alpha\right)\left(\omega_{1 \mathrm{H}}-\frac{1}{2} S^{\mathrm{H}}\right) & =0 \\
\lambda_{2} \omega_{2} & =\frac{1}{2} \lambda_{1 \mathrm{~L}} S^{\mathrm{L}}+\frac{1}{2} \lambda_{1 \mathrm{H}} S^{\mathrm{H}} .
\end{aligned}
$$

If $\lambda_{1 \mathrm{~L}}=0$, then optimality of $d_{1}$ in the low state implies $\alpha=0$, and $\lambda_{2}=0$, and then the third warrant equation implies $\lambda_{1 \mathrm{H}}=0$, which is a contradiction (since the theorem requires $(\lambda, \omega) \neq 0$ ). Thus $\lambda_{1 \mathrm{~L}}$ is strictly positive, which implies $\omega_{1 \mathrm{~L}}=U_{1 \mathrm{~L}}$. And because $\lambda_{1 \mathrm{~L}}$ is strictly positive, the third warrant equation implies that $\lambda_{2}$ and $\omega_{2}$ are also 
strictly positive, and so $\omega_{2}=U_{2}=\mu_{2} S^{\mathrm{H}}>0$. Thus $\mu_{2}>0$, so $d_{2}$ is optimal. Since both decisions are optimal in both states, $\alpha$ must satisfy the equations

$$
\begin{aligned}
\alpha & =\lambda_{1 \mathrm{~L}}-\lambda_{2}(1-\tau) \\
& =\lambda_{2} \tau-\lambda_{1 \mathrm{H}} .
\end{aligned}
$$

Thus

$$
\lambda_{2}=\lambda_{1 \mathrm{~L}}+\lambda_{1 \mathrm{H}}>0 .
$$

Since $\alpha+\lambda_{1 \mathrm{H}}=\tau \lambda_{2}>0$, the second warrant equation implies $\omega_{1 \mathrm{H}}=\frac{1}{2} S^{\mathrm{H}}$, and since $\lambda_{1 \mathrm{~L}}>0$ the first warrant equation then implies $\omega 1 \mathrm{~L}=\omega_{1 \mathrm{~L}}=\frac{1}{2} S^{\mathrm{L}}=U_{1 \mathrm{~L}}$ (by complementary slackness), and this implies

$$
\mu_{1}=1-\frac{1}{2} \frac{S^{\mathrm{L}}}{S^{\mathrm{H}}}
$$

Then $U_{1 \mathrm{H}}=S^{\mathrm{H}}-\frac{1}{2} S^{\mathrm{L}}$, while $\omega_{1 \mathrm{H}}=\frac{1}{2} S^{\mathrm{H}}$, so $\omega_{1 \mathrm{H}}<U_{1 \mathrm{H}}$, and all of the complementary slackness conditions are satisfied, with $\lambda_{1 \mathrm{H}}=0$ and $\lambda_{2}=\lambda_{1 \mathrm{~L}}$ and $\alpha=\tau \lambda_{2}$.

Since $\tau S^{\mathrm{H}}<S^{\mathrm{L}}$, the optimal mechanism for player 2 is a pooling demand, with $\mu_{1}=1-S^{\mathrm{L}} / S^{\mathrm{L}}$, while the optimal mechanism for player 1 sets $\mu_{1}=1$. So the NBS is implemented by the random dictator mechanism (i.e. by randomly selecting the optimal mechanism for one player or the other, with equal probabilities). Thus, it has been shown that the NBS is unique, and that it gives player 2 half of the low surplus, with player 1 getting the residual.

\section{APPENDIX B. ARE INFORMATIONAL RENTS BIGGER WHEN MORE INFORMATION IS PRIVATE?}

When an uninformed seller makes offers to a buyer whose valuation is drawn privately from some known distribution, the optimal offer for the seller may be a pooling offer that concedes an informational rent to the buyer. In that case a small improvement in the distribution of the buyer's valuations implies an increase in the informational rent. More generally, one might expect that when the buyer's informational advantage increases, the informational rent increases as well. But this is not always true. For example, a large improvement in the distribution may cause the seller to switch from a pooling to a screening offer, and in some cases this completely eliminates the informational rent. And in the case where partial pooling is initially optimal, even a small improvement induces the seller to screen more aggressively, with the possibility that the informational rent is reduced. The purpose of this Appendix is to examine this possibility, for a limited but interesting class of distributions.

Consider a seller making a take-it-or-leave-it demand to a buyer whose valuation is $a+s$, with $a \geq 0$ and $s$ distributed over the interval $[0, b]$. Let $y=s / b$, distributed on $[0,1]$ according to the distribution function $F$. The seller's payoff from a demand $a+b x$ is zero if this demand exceeds the actual surplus, which is the case if $x>y$. Thus, the seller's expected payoff is $(a+b x) /(1-F(x))$. The question is whether an increase in $b$ leads to an increase in the informational rent.

Suppose that $F$ is a beta distribution, with density

$$
f(x)=\frac{\Gamma(\alpha+\beta)}{\Gamma(\alpha) \Gamma(\beta)} x^{\alpha-1}(1-x)^{\beta-1},
$$

where $\Gamma$ is the gamma function, with $\alpha>0$, and $\beta>0$. Two subsets of this class of distributions will be analysed, one (Case A) defined by taking $\beta=1$ with $\alpha>1$, so that $x$ has a power distribution with an increasing density, and the other (Case B) defined by taking $\alpha=1$ (with no restriction on $\beta$ ), so that $1-x$ has a power distribution. The uniform distribution is included in Case B (and it is on the boundary of Case A).

The following lemma will be used in the analysis of Case A.

Lemma 3. The function

$$
f(\alpha)=\frac{1-z^{\alpha}}{\alpha}
$$

is decreasing in $\alpha$, for $z>0$. 
Proof. The derivative of $f$ is

$$
f^{\prime}(\alpha)=\frac{-\left(1-z^{\alpha}\right)-\alpha z^{\alpha} \log (z)}{\alpha^{2}}
$$

Let $y=-\alpha \log (z)$. Then

$$
\alpha^{2} f^{\prime}(\alpha)=e^{-y}(1+y)-1 \leq 0
$$

where the inequality holds because $e^{y} \geq 1+y$ (with equality when $y=0$, which means $z=1$ ). Thus $f$ is decreasing.

Case A Suppose $F$ is a beta distribution with $\beta=1$ and $\alpha>1$. In this case pooling is never optimal, since $f(0)=0$. Let $z$ be the optimal screening price. The seller's objective function is strictly concave, and $z \in(0,1)$ is the unique solution of the first-order condition

$$
\left(1-z^{\alpha}\right)-\alpha z^{\alpha-1}\left(\frac{a}{b}+z\right)=0
$$

This equation can be rewritten as

$$
b=\frac{a \alpha}{z^{1-\alpha}-(1+\alpha) z} .
$$

This gives $b$ as a strictly increasing function of $z$, meaning that the optimal screening price is strictly increasing in $b$. That being so, the informational rent $R$ is increasing in $b$ if and only if $R$ is increasing in $z$. Using equation (97), the relationship between $R$ and $z$ is given by

$$
R=\frac{b}{1+\alpha}\left(\alpha-(1+\alpha) z+z^{1+\alpha}\right)=\frac{a \alpha}{1+\alpha} \frac{\alpha-(1+\alpha) z+z^{1+\alpha}}{z^{1-\alpha}-(1+\alpha) z}
$$

Taking derivatives and simplifying the result gives

$$
\frac{1+\alpha}{a \alpha} \frac{d R}{d z}=\frac{\alpha-1-(1+\alpha)\left(z-z^{\alpha}+z^{1+2 \alpha}\right)+2 z^{1+\alpha}}{\left(1-(1+\alpha) z^{\alpha}\right)^{2}} .
$$

Thus $R$ is increasing in $z$ (and therefore in $b$ ) if and only if the numerator of the expression on the right side of this equation is non-negative. The first-order condition determining the screening price implies that

$$
1-(1+\alpha) z^{\alpha} \geq 0
$$

Thus

$$
z^{1+\alpha}-(1+\alpha) z^{1+2 \alpha} \geq 0
$$

So it is enough to show that

$$
\psi(z)=\alpha-1-(1+\alpha)\left(z-z^{\alpha}\right)+z^{1+\alpha} \geq 0
$$

The derivative of $\psi$ is given by

$$
\psi^{\prime}(z)=(1+\alpha)\left(z^{\alpha}+\alpha z^{\alpha-1}-1\right)
$$

Since $\psi^{\prime}(0)<0<\psi^{\prime}(1)$ and $\psi^{\prime \prime}(z)>0$, the function $\psi$ has a unique minimum, say at $z_{0}$. So it is enough to show that $\psi\left(z_{0}\right) \geq 0$. Note that

$$
\psi\left(z_{0}\right)=\psi\left(z_{0}\right)-\frac{z_{0} \psi^{\prime}\left(z_{0}\right)}{1+\alpha}=\alpha-1-\alpha z_{0}+z_{0}^{\alpha},
$$

since $\psi^{\prime}\left(z_{0}\right)=0$. Thus $\psi\left(z_{0}\right) \geq 0$ if and only if

$$
\alpha \geq \frac{1-z_{0}^{\alpha}}{1-z_{0}}
$$


This is an immediate implication of Lemma $\mathrm{B}$, because $f(1) \geq f(\alpha)$ for $\alpha>1$. Thus, it has been shown that although pooling is never optimal for a power distribution with exponent greater than one, the informational rent nevertheless increases when the extent of the employer's private information is magnified.

Case B Suppose $F$ is a beta distribution with $\alpha=1$. The simplest example is the uniform distribution (with $\beta=1$ ). The informational rent is

$$
R=b \int_{x}^{1}(1-t)^{\beta} d t=\frac{b(1-x)^{\beta+1}}{\beta+1} .
$$

The derivative of the worker's objective function is given by

$$
\begin{aligned}
H^{\prime}(x) & =(1-x)^{\beta}-\beta(1-x)^{\beta-1}(c+x) \\
& =(1-x)^{\beta-1}(1-\beta c-(1-\beta) x),
\end{aligned}
$$

where $c=a / b$. If $\beta c \geq 1$ then $H^{\prime}(x) \leq 0$ for all $x$, so pooling is optimal. If $\beta c \leq 1$ then $H^{\prime}(x)>0$ for all $x<x^{*}$, and $H^{\prime}(x)<0$ for all $x>x^{*}$, where $x^{*}$ is given by

$$
x^{*}=\frac{1-\beta c}{1-\beta} .
$$

Also, $H\left(x^{*}\right)=0$, so screening at $x^{*}$ is optimal. Thus, the mapping from $b$ to $R$ is given by

$$
R(b)=\left\{\begin{array}{ll}
\frac{b}{\beta+1} & b \leq a \beta \\
\frac{b}{\beta+1}\left(\frac{\beta}{\beta+1}\right)^{\beta+1}\left(1+\frac{a}{b}\right)^{\beta+1} & b \geq a \beta
\end{array} .\right.
$$

The function $R(b)$ is obviously increasing in the pooling region. To show that it increasing in the screening region, it is enough to show that $b\left(1+\frac{a}{b}\right)^{\beta+1}$ is increasing in $b$, for $b \geq a \beta$, or equivalently that the function

$$
\omega(z)=z\left(1+\frac{1}{z}\right)^{\beta+1}
$$

is increasing in $z$, for $z \geq \beta>0$. The derivative of this function is

$$
\begin{aligned}
\omega^{\prime}(z) & =\left(1+\frac{1}{z}\right)^{\beta+1}-(\beta+1)\left(1+\frac{1}{z}\right)^{\beta} \frac{1}{z} \\
& =\left(1+\frac{1}{z}\right)^{\beta}\left(1-\frac{\beta}{z}\right),
\end{aligned}
$$

which is non-negative for $z \geq \beta$, so the function is increasing.

Thus, it has been shown that for any beta distribution with $\alpha=1$, the informational rent increases when the extent of the employer's private information is magnified, even though this induces the worker to switch from a pooling price to a screening price. ${ }^{12}$

Acknowledgements. I thank Björn Brügemann, Bob Hall, Rasmus Lentz, Giuseppe Moscarini, Chris Pissarides, Rob Shimer and the participants in seminars at Northwestern, Yale and Duke for useful comments. I also thank the editor and two anonymous referees for their constructive criticism. I am particularly grateful to Rob Shimer for pointing out a serious mistake in early versions of the paper. The National Science Foundation provided research support.

\section{REFERENCES}

BALKENBORG, D. (2006), "Judgment-Proofness and Extended Liability in the Presence of Adverse Selection", in M. Boyer, Y. Hiriart and D. Martimort (eds.) Frontiers in the Economics of Environmental Regulation and Liability (Aldershot: Ashgate).

12. Note that the rent function $R(b)$ is continuous (but not differentiable) at the point where screening becomes optimal. 
BEAUDRY, P. and DINARDO, J. (1991), "The Effect of Implicit Contracts on the Movement of Wages Over the Business Cycle: Evidence from Micro Data", The Journal of Political Economy, 99 (4), 665-688.

BRÜGEMANN, B. (2005), "Vintage Productivity Shocks and Employment Fluctuations" (Yale University).

BRÜGEMANN, B. and MOSCARINI, G. (2009), "Rent Rigidity, Asymmetric Information, and Volatility Bounds in Labour Markets" (Working Paper No. 13030, National Bureau of Economic Research).

COSTAIN, J. S. and REITER, M. (2008), "Business Cycles, Unemployment Insurance, and the Calibration of Matching Models", Journal of Economic Dynamics and Control, 32 (4), 1120-1155.

DUNNE, T., FOSTER, L., HALTIWANGER, J. and TROSKE, K. R. (2004), "Wage and Productivity Dispersion in United States Manufacturing: The Role of Computer Investment", Journal of Labor Economics, 22 (2), $397-429$.

ELSBY, M. W. L., MICHAELS, R. and SOLON, G. (2009), "The Ins and Outs of Cyclical Unemployment", American Economic Journal: Macroeconomics, 1 (1), 84-110.

FUJITA, S. and RAMEY, G. (2009), "The Cyclicality of Separation and Job Finding Rates", International Economic Review, 50 (2), 415-430.

GERTLER, M. and TRIGARI, A. (2009), "Unemployment Fluctuations with Staggered Nash Wage Bargaining", Journal of Political Economy, 117 (1), 38-86.

HAGEDORN, M. and MANOVSKII, I. (2008), "The Cyclical Behavior of Equilibrium Unemployment and Vacancies Revisited”, American Economic Review, 98 (4), 1692-1706.

HALL, R. E. (2005), "Employment Fluctuations with Equilibrium Wage Stickiness", The American Economic Review, 95 (1), 50-65.

HALL, R. E. (2006), "Job Loss, Job Finding and Unemployment in the U.S. Economy Over the Past 50 Years", NBER Macroeconomics Annual, 20, 101-166.

HALL, R. E. and MILGROM, P. R. (2008), "The Limited Influence of Unemployment on the Wage Bargain", American Economic Review, 98 (4), 1653-1674.

HORNSTEIN, A., KRUSELL, P. and VIOLANTE, G. L. (2005), "Unemployment and Vacancy Fluctuations in the Matching Model: Inspecting the Mechanism”, Federal Reserve Bank of Richmond Economic Quarterly, 91 (3), 19-51.

HOSIOS, A. J. (1990), "On the Efficiency of Matching and Related Models of Search and Unemployment", The Review of Economic Studies, 57 (2), 279-298.

KENNAN, J. (1986), The Economics of Strikes, Volume 2, Handbook of Labor Economics (Elsevier) 1091-1137.

KENNAN, J. (2001), "Uniqueness of Positive Fixed Points for Increasing Concave Functions on $r^{n}$ : An Elementary Result", Review of Economic Dynamics, 4 (4), 893-899.

MENZIO, G. (2005), "High Frequency Wage Rigidity" (Working paper, University of Pennsylvania).

MORTENSEN, D. T. and NAGYPÁL, E. (2007), "More on Unemployment and Vacancy Fluctuations", Review of Economic Dynamics, 10 (3), 327-347.

MORTENSEN, D. T. and PISSARIDES, C. A. (1994), "Job Creation and Job Destruction in the Theory of Unemployment", The Review of Economic Studies, 61 (3), 397-415.

MYERSON, R. B. (1984), "Two-Person Bargaining Problems with Incomplete Information”, Econometrica, 52 (2), 461-487.

NAGYPÁL, É (2005), "Labor-Market Fluctuations, On-The-Job Search, and the Acceptance Curse" (Northwestern University, December 2005).

PISSARIDES, C. A. (forthcoming), "The Unemployment Volatility Puzzle: Is Wage Stickiness the Answer?" Econometrica.

ROTEMBERG, J. J. (2006), "Cyclical Wages in a Search-and-Bargaining Model with Large Firms", NBER International Seminar on Macroeconomics, 3, 65-114.

SHIMER, R. (2005), "The Cyclical Behavior of Equilibrium Unemployment and Vacancies", The American Economic Review, 95 (1), 25-49.

SHIMER, R. (2007), "Reassessing the Ins and Outs of Unemployment" (Working Paper 13421, National Bureau of Economic Research).

YASHIV, E. (2006), "Evaluating the Performance of the Search and Matching Model", European Economic Review, 50 (4), 909-936. 